\title{
Who Cares about Relative Deprivation?
}

\author{
Martin Ravallion and Michael Lokshin ${ }^{1}$ \\ Development Research Group, World Bank
}

\begin{abstract}
Theories of relative deprivation predict negative welfare effects when friends and neighbors become better-off. Other theories point to likely positive benefits. We test for perceived welfare effects of relative deprivation in one of the world's poorest countries, Malawi, using data and methods that help address likely biases in past tests. We find that relative deprivation is not a concern for most of our sample, although it is for the comparatively well off. Our results provide a welfarist explanation for the high priority given to absolute poverty in poor countries. The pattern of externalities suggests that there will be too much poverty and inequality from the point of view of aggregate efficiency.
\end{abstract}

Keywords: Poverty, relative deprivation, risk-sharing, externalities, subjective welfare

JEL: D63, I31, O12

World Bank Policy Research Working Paper 3782, December 2005

The Policy Research Working Paper Series disseminates the findings of work in progress to encourage the exchange of ideas about development issues. An objective of the series is to get the findings out quickly, even if the presentations are less than fully polished. The papers carry the names of the authors and should be cited accordingly. The findings, interpretations, and conclusions expressed in this paper are entirely those of the authors. They do not necessarily represent the view of the World Bank, its Executive Directors, or the countries they represent. Policy Research Working Papers are available online at http://econ.worldbank.org.

1 The authors are grateful to Kathleen Beegle for discussions about the data used here. Helpful comments on this paper were received from Tony Atkinson, Kathleen Beegle, Quy-Toan Do, Jed Friedman, Garance Genicot, David Ribar, Dominique van de Walle, Michael Woolcock and seminar participants at George Washington University and the World Bank.

Addresses for correspondence: Martin Ravallion, World Bank, 1818 H Street, NW, Washington DC, 20433, e-mail:mravallion@worldbank.org, and Michael Lokshin, World Bank, 1818 H Street, NW, Washington DC, 20433, e-mail:mlokshin@worldbank.org. 


\section{Introduction}

Discussions about how best to fight poverty in poor countries have typically focused on peoples’ absolute levels of living, as measured by their command over commodities. This focus is at odds with a large body of work in sociology, social psychology and economics arguing that relative economic position is the carrier of utility, not absolute consumption; this is often called the theory of 'relative deprivation' (RD), following Runciman (1966). ${ }^{2}$ The importance of RD has long been debated in economics, though early discussions had little or no empirical evidence to draw upon. ${ }^{3}$ More recently, evidence of RD has come from a variety of sources, though almost solely for developed countries. ${ }^{4}$ An overview of the evidence concludes that:

"In sum, the claim that satisfaction depends heavily on relative position is supported by considerable evidence from both the psychological literature on subjective well-being and by at least fragmentary evidence from the behavioural economics literature. I am aware of no empirical or theoretical evidence against the claim.” (Frank, 1997, p.1836)

Finding evidence of RD effects in poor countries as strong as those found in rich ones would cast serious doubt on the welfare-economic justifications for many current development policies. Consider, for example, Luttmer’s (2005) striking finding in regressions for selfassessed happiness in the US that the coefficients on log income and log mean 'neighbors' income add up to roughly zero. This implies that an equal proportionate increase in all incomes (leaving relative inequality unchanged) would have no impact on average happiness. A result as strong as this would clearly lead one to question the emphasis currently placed on promoting

2 There is a large literature; other contributions include Easterlin $(1974,1995)$, Townsend (1979), van de Stadt et al., (1985), Akerlof and Yellen (1990), Frank (1985, 1997), Oswald (1997), Solnick and Hemenway (1998), Walker and Smith (2001) and Alpizar et al. (2005).

3 See, for example, Becker's (1974) discussion of the differing views of Adam Smith and Thorstein Veblan concerning (in effect) the welfare relevance of RD.

$4 \quad$ In a well-known example, Easterlin (1974) used RD to explain why the proportion of people who think they are happy has not changed much over time in the US, despite economic growth. Also see Oswald (1997) and Blanchflower and Oswald (2004). Evidence from micro data is reviewed by Oswald (1997) and Frank (1997); we cite example later. 
economic growth in poor countries. Negative externalities in consumption from RD would also suggest that poor people face inefficiently high incentives to escape poverty, because they do not take account of the negative spillover effects of their income gains on social comparators. By this view, promoting poverty reduction would entail welfare efficiency costs — pointing to a potentially important trade-off for development policy.

At a conceptual level, one can agree in principle that poverty is absolute in the space of 'welfare,' but relative in the space of commodities. To make that idea operational in a scientifically credible way we need to be able to identify how individual welfare is affected by relativity incomes or consumptions. Here we follow a long tradition in economics of identifying 'welfare' with utility, though we acknowledge that this is by not universally accepted; in particular, Amartya Sen argues that for the purpose of measuring poverty, 'welfare' should be defined in terms of 'capabilities' not 'utilities;' see, for example, Sen (1983). ${ }^{5}$

There are some clues about the possible important of $\mathrm{RD}$ from qualitative work. Drawing on village-level observations, Rao (2001) argues that perceptions of 'status and rank’ matter in rural India. Similarly, some of the qualitative reports from field work found in Narayan and Petesch (2002) are suggestive of concerns about status and position. ${ }^{6}$ While such field studies can be insightful, they offer no guidance on the quantitative importance of RD, and they contain ambiguities about even its qualitative importance to poor people relative to other factors. ${ }^{7}$ Rigorous quantitative evidence on this issue for poor countries has been virtually non-existent.

$5 \quad$ These views are not mutually exclusive. We can interpret a standard utility function defined on commodities and personal characteristics as a derived function, obtained by substituting a model of the functionings relevant to capabilities into a (primal) utility function defined on those functionings; see Ravallion (2005) for a more formal treatment.

$6 \quad$ Writing about poor people in Nigeria it is claimed that, "In addition to material deprivation, the people ... speak of lacking dignity, status, security and hope” (Narayan and Petesch, 2002, p.107). $7 \quad$ For example, in the quote from Narayan and Petesch in the last footnote, it can be argued that 'security' is a positive external effect of higher group welfare not a negative one, as in RD. 
Other theories and evidence point in a different direction, by suggesting how poor people can share in economic gains to friends and neighbors. Risk sharing arrangements are prominent in the development literature, given the uninsured risks and prospects of falling into permanent destitution. ${ }^{8}$ Communities can also be important institutions for providing employment and local public goods — generating positive externalities for the poor in relatively well-off areas. ${ }^{9}$

Positive externalities may arise via one's current economic welfare or be an independent effect, such as through greater personal security in the presence of uninsured risks. Since it is repeated interpersonal interaction that facilitates both social comparison and mutual support or collective action, it is not surprising that these conceptually distinct theoretical perspectives point to similar social groups — neighbors, friends, co-workers — as the generators of the external effects.

This paper provides direct tests for RD in one of the world's poorest countries, Malawi. Almost 90\% of Malawi's population lives in rural areas, where the vast majority of households are small-holders who depend heavily on rain-fed, highly risk-prone and seasonal, traditional agriculture. ${ }^{10}$ In the late 1990s, roughly two-thirds of the population lived in households with consumption per person below the country’s poverty line (National Economic Council, 2000). Yet income inequality is relatively high, with a Gini index around 0.50 (World Bank, 2005a). As in any risk-prone and poor rural economy there are various forms of informal insurance and social assistance in rural Malawi. An example is the widespread local institution called ganyu, whereby households in current need are provided some form of unskilled piecework in return for

\footnotetext{
$8 \quad$ There is a large literature assessing the safety-net role of private transfers and other forms of support in poor countries; see, for example, Ravallion and Dearden (1988), Coate and Ravallion (1993), Murgai et al. (2002), Ligon et al., (2002), Fafchamps and Lund (2003), Maitra and Ray (2003) and Cox et al. (2004). There is also evidence of such effects amongst poor families in the US (Ribar, 2005).

$9 \quad$ For an interesting perspective on the role of communities see Bowles and Gintis (2002). In a development context, see Mansuri and Rao (2004). Jalan and Ravallion (2002) find evidence of positive externalities for poor rural households living in areas with better-off neighbors (in southwest China). 10 Broader discussions of poverty in Malawi can be found in Ellis et al., (2003) and Peters (2004).
} 
food or cash, typically by better-off benefactors within the community. It seems that Ganyu is often more than simply a labor-market transaction, but is a form of social assistance within communities, embedded in established and reciprocal relationships. ${ }^{11}$ This is clearly an important source of positive external effects for poor people in Malawi, as long as they have better-off friends and neighbors to turn to. But is it more important than RD?

We begin by asking when $\mathrm{RD}$ will be the dominate welfare effect in a simple model combining informal risk-sharing with the idea of a 'positional good.' Under certain conditions, the direction of the welfare effect will reverse sign as income rises, with RD only emerging as the dominant concern at high incomes. The model motivates our tests for Malawi. We offer an empirical method of testing for RD that helps address the main problems that have clouded inferences in past work. After discussing the sources of bias in past tests (section3), we describe our data and methods (section 4). Section 5 presents our results; we find that for Malawi’s poor, the positive effects of better-off friends and neighbors dominate concerns about RD. However, we do find evidence of RD effects at higher level of living. The positive externalities are largely confined to rural areas, while (for at least some specifications) the negative externality from RD is the dominant social effect in urban areas. Section 6 presents our main conclusions.

\section{An encompassing model}

Our empirical work will study the relationship between survey responses on overall satisfaction with life (interpreted as an indicator of utility) and various measures of the material standard of living ('economic welfare') of both the respondent and comparison groups. In other words, we aim to estimate a utility function, $v\left(y, y^{n}\right)$, which depends on own-income, $y$ and

$11 \quad$ See Englund (1999), Whiteside (2000) and Mtika (2001); with reference to ganyu, Whiteside writes that "Providing food in exchange for work may be as much a social obligation for those with food as a response to work needing doing” (p.2). 
income of (say) 'neighbors,' $y^{n}$. Before delving into the estimation problems and data it is of interest to see how such a utility function can be derived from more primitive choice-theoretic assumptions. To do this we assume that an informal risk-sharing arrangement exists amongst a set of self-interested individuals. We consider two homogeneous groups, one of which draws the income $y$ while the other gets $y^{n}$. The risk-sharing arrangement is in place prior to the realization of an uncertain process which assigns people to these groups at each date. The incomes are random variable, reflecting the risks faced in a (largely rural) developing economy.

To derive $v\left(y, y^{n}\right)$, let utility depend on the quantities consumptions of two composite commodities, $X_{1}$ and $X_{2}$. Utility from $X_{1}$ depends on one's own consumption, but for $X_{2}$ it depends on consumption relative to the other group, making it a 'positional good.' One can think of $X_{1}$ as a good which is consumed in private while consumption of $X_{2}$ is public knowledge within the community and so it gives status in the specific social context, leading to consumption rivalries.

Utility is $u\left(X_{1}, X_{2}-X_{2}^{n}\right)$ when neighbors consume $X_{2}^{n}$ of the positional good. ${ }^{12}$ Utility is strictly increasing and quasi-concave and the budget constraint is:

$$
X_{1}+p X_{2}=y+\tau\left(y, y^{n}\right)=Y
$$

where $\tau\left(y, y^{n}\right)$ is the monetary value of the support (in cash or kind) received by a person with pre-transfer income $y$ in $\left[y^{\min }, y^{\max }\right]$ when the neighbors have the pre-transfer income $y^{n}$. (We use lower case $y$ to denote pre-transfer income and upper case $Y$ for post-transfer and similarly for $y^{n}$ and $Y^{n}$.) We assume that $\tau\left(y, y^{n}\right)>0$ if $y<y^{n}$ and $\tau\left(y, y^{n}\right)+\tau\left(y^{n}, y\right)=0$.

12 Notice that we assume that it is the difference $X_{2}-X_{2}^{n}$ that matters not the ratio $X_{2} / X_{2}^{n}$. That is not essential, though it simplifies the analytics. 
The function $\tau$ is decided prior to knowing the actual state-specific incomes, with consumption choices being made in each realized state of nature, taking the transfers as given. The folk theorem can be used to motivate this risk-sharing arrangement as the outcome of a repeated non-cooperative game in which defectors are penalized by being excluded from the game for ever after. Full risk-sharing (income-pooling) requires that $\tau\left(y, y^{n}\right)=y^{n}-y$, so that everyone ends up with $y^{n} \cdot{ }^{13}$ However, to be feasible, the transfers must satisfy the constraint that the gain from continued participation in the risk-sharing arrangement is no less than the gain from defection. When full-risk sharing is not attainable, the equilibrium $\tau\left(y, y^{n}\right)$ is the maximum amount that can be taken from the person with higher realized income without inducing defection, given the cost of that defection (Coate and Ravallion, 1993). ${ }^{14}$

There are other possible interpretations of $\tau\left(y, y^{n}\right)$. The positive externality of a higher $y^{n}$ might arise instead from the financing arrangements for a local public good, the quantity of which is subsumed in the direct utility function $u$. Then $\tau\left(y, y^{n}\right)(<0)$ can then be thought of the charge levied on those who draw the income $y$ in a community with mean income $y^{n}$.

The implied demand functions are $X_{i}\left[y+\tau\left(y, y^{n}\right), X_{2}^{n}, p\right](i=1,2)$ and the corresponding demand functions for the neighbors are $X_{i}\left[y^{n}-\tau\left(y, y^{n}\right), X_{2}, p\right]$. We assume that these functions are non-decreasing in incomes, implying marginal propensities to spend that are non-negative and bounded above by unity for both goods and both groups. The indirect utility function is:

13 The property can be relaxed to allow post-transfer income inequality with full risk sharing by introducing a risk-free idiosyncratic income component.

$14 \quad$ Coate and Ravallion derive a function of the form $\tau\left(y, y^{n}\right)$ as the solution to a repeated noncooperative game in which each player faces an independent and uncertain income stream with $\left(y, y^{n}\right)$ as the possible draws in a given state of nature. They characterize the solution for the case in which utility depends on own income, and compare this to the optimal insurance scheme. Extending their analysis to the present situation of externalities would not appear to be difficult (the simplest approach would assume that utility is separable between own income and neighbor's income.) 


$$
v\left(y, y^{n}\right) \equiv \widetilde{v}\left[y+\tau\left(y, y^{n}\right), X_{2}^{n}, p\right]=\max \left[u\left(X_{1}, X_{2}-X_{2}^{n}\right) \mid X_{1}+p X_{2}=y+\tau\left(y, y^{n}\right)\right]
$$

(The corresponding utility function for the neighbors is $v\left(y^{n}, y\right)$.) Applying the envelope theorem to (2), we find that:

$$
\operatorname{sign} \frac{\partial v}{\partial y^{n}}=\operatorname{sign}\left[\frac{\partial \tau}{\partial y^{n}}-p \frac{\partial X_{2}^{n}}{\partial Y^{n}}\left(1+p \frac{\partial X_{2}^{n}}{\partial Y^{n}}\right)^{-1}\right]
$$

This captures the two opposing effects: the positive return to neighbors becoming better off and hence more generous $\left(\partial \tau / \partial y^{n}>0\right)$ versus enhanced relative deprivation $\left(\partial X_{2}^{n} / \partial Y^{n}>0\right)$.

Three special cases are instructive about the range of possible outcomes.

Case 1: Full risk-sharing. It is plain from (3) that the positive effect will always dominate the RD effect under full risk sharing. Then $\partial v / \partial y^{n}>0$, given that $\partial \tau / \partial y^{n}=1$ and $p \partial X_{2}^{n} / \partial Y^{n} \geq 0\left(p \partial X_{2}^{n} / \partial Y^{n}>-1\right.$ is all that is strictly required). With full risk sharing, RD cannot be the dominant social effect in this model at any income level.

Case 2: Partial risk-sharing with small transfers: With partial risk-sharing, the equilibrium transfer is the maximum that can be sustained without inducing the donor's defection, i.e., $\tau\left(y, y^{n}\right)$ is defined implicitly by equating the donor's benefit from defection with the utility-cost of defecting, $c:^{15}$

$$
\left.v\left(y^{n}, y\right)-v\left[y^{n}-\tau\left(y, y^{n}\right), y\right]=c \quad\left(\text { for } y^{n}>y\right)\right)
$$

We can treat $c$ as exogenously fixed, implying that:

$$
\frac{\partial \tau}{\partial y^{n}}=1-\frac{\partial v\left(y^{n}, y\right) / \partial y^{n}}{\partial v\left(y^{n}-\tau, y\right) / \partial y^{n}}
$$


It is clear from (5) that for small transfers, the maximum possible $\tau$ without inducing defection is unresponsive to changes in $y^{n}$. Setting $\partial \tau / \partial y^{n}=0$ in (3) it is evident that when efficient risksharing is not feasible and transfers are small, RD will dominate $\left(\partial v / \partial y^{n}<0\right)$.

Between these extremes, stronger assumptions are needed to determine the direction of the welfare effect with large transfers that fall short of full risk sharing. Nor can it be presumed that the external effect will have the same sign whatever the level of own-income. This is illustrated by the following case.

Case 3: Partial risk sharing, non-negligible transfers and an interaction effect. In this special case, the positive externality dominates for the poor, but this switches at sufficiently high incomes, when $\mathrm{RD}$ becomes the dominant social effect. To see how this can happen, notice first that (from equation 3), there are two ways that differences in own-income $y$ could affect the balance between the two opposing external effects. The first is through an interaction effect between own income and neighbors' income in the transfer function and the second is through any own-income effect on neighbors' marginal propensity to consume the positional good. Let us close off the first effect by assuming that the utility function is separable between $y$ and $y^{n}$, so that the marginal propensity to transfer, $1>\partial \tau / \partial y^{n}>0$, does not depend on $y$. The first term on the RHS of (3) is thus a constant.

Focusing on the second term in (3), Case 3 assumes that the marginal propensity to consume the positional good is very low at low incomes. Our idea here is that when both incomes are very low, social rivalries are likely to be dominated by the attainment of basic needs for survival. ${ }^{16}$ So we set $p \partial X_{2}^{n} / \partial Y^{n}$ sufficiently close to zero at $y^{\min }$ such that $\partial v / \partial y^{n}>0$. At

16 We do not need a kink in the demand functions, which can still be continuous with continuous first derivatives. All we require is that the income gradient is sufficiently low at low incomes. 
higher incomes, the social aspect of the positional good starts to influence budget allocations; in particular, we assume that the neighbor's marginal propensity to spend on the positional good rises to near unity at $y^{\max }$ (the boundary condition can be relaxed without changing the result). Then $\partial v / \partial y^{n}<0$ at $y=y^{\max }$. By continuity there will be a unique switch point in the income space, below which $\partial v / \partial y^{n}>0$ and above which $\partial v / \partial y^{n}<0$. We will look for such an interaction effect in our data.

\section{Issues in testing for relative deprivation}

Past econometric tests for welfare effects of relative deprivation have regressed self-rated welfare (satisfaction with life or happiness) on both own income and an estimate of comparison group income, namely the mean income of people living in the same area or working in the same industry or with similar characteristics (age, education, occupation). ${ }^{17}$ Almost all studies using this method have found a negative welfare effect of comparison-group income. ${ }^{18}$ This section identifies a number of problems with this approach, some of which suggest that it will be biased toward finding signs of RD when it is not in fact present. Our alternative test using subjective economic welfare avoids these concerns, though it introduces some potential new sources of bias, which we also discuss.

Identifying the comparison group and measuring its welfare

One concern with the standard approach in the literature is that the researcher must make an a priori judgment about the relevant comparison group. Yet this can vary greatly from person

17 Examples of the various approaches can be found in Stadt et al. (1985), Clark and Oswald (1996), Pradhan and Ravallion (2000), Ravallion and Lokshin (2002), McBride (2001), Blanchflower and Oswald (2004), Senik (2004), Ferrer-i-Carbonell (2005) and Luttmer (2005).

18 An exception is Senik (2004) who finds a positive effect, which she attributes to the fact that her data are for a transition economy, namely Russia 
to person. It has been argued that “.. comparisons are most salient if individuals perceive the reference person or group as in some way similar to themselves” (Kahneman and Varey, 1991, p. 140; also see Runciman, 1966). But that is based on the individual's own judgment, given idiosyncratic informational and social factors that a researcher would have a very hard time observing in any systematic way. Neither psychological nor economic theories of RD offer much insight into who constitutes the relevant comparison group. The researcher must make some potentially strong identifying assumptions.

A further concern is that differences in the objective economic welfare of one's neighbors can hardly be relevant to RD, or the security that may come from knowing that friends and neighbors are capable of coming to one's aid, $\underline{\text { unless }}$ those differences are known and perceived as relevant. The objective circumstances will undoubtedly matter to some channels by which the external effect is transmitted, such as capacity to pay for local public goods. However, in accounting for differences in overall well-being, it can be argued that the subjective assessment is likely to matter more than the objective one. The objective measure can be thought of as a poorly measured proxy for the true perception of the comparison group’s welfare. Assuming classical measurement errors, attenuation biases can be expected, although the errors could also be correlated with the dependent variable in this case, clouding the direction of bias.

Nor has the literature tested for interaction effects. If the external effect switches sign as income rises (as suggested by Case 3 in section 2) then not allowing for this interaction effect could suggest little or no relationship, by averaging across the positive and negative effects.

A potentially important source of interaction effects in a developing country is urbanization. It can be conjectured that community-based risk sharing and collective action erodes with urbanization; the repeated interaction amongst essentially the same group of people 
that sustains informal risk-sharing arrangements may well be more common in village-based societies than urban areas with more mobile populations. ${ }^{19}$ Comparing how our tests for relative deprivation differ between urban and rural areas also offers a clue as to how the importance of relative poverty might change over time, as the economy becomes more urbanized.

In the light of the above observations, we take two approaches to testing. In both cases, our dependent variable is provided by the answers to a 'satisfaction with life' (SWL) question. (The question does not refer to any specific aspect of 'satisfaction with life'. We give the precise question used in section 3.2.) This has probably been the most widely used question for assessing overall well-being in psychology and economics. ${ }^{20}$ We shall do one test for $\mathrm{RD}$ that is similar to the methods used in past research, except that we allow for interaction effects. This method uses a standard objective measure of economic welfare based on consumption, including that of the geographic area in which the respondent lives. However, our data and methods allow us to take a different approach that avoids the need to pre-judge the comparison group and the precise welfare metric. For this purpose, questions were added to the Malawi survey on the respondent's assessments of the economic welfare of the family's 'friends' and 'neighbors.' This has the advantage that it is tailor-made to the perceptions of the respondent. However, as we also discuss below, that advantage comes with the drawback that there may be latent variables that jointly influence both the respondent's overall satisfaction with life and how she perceives the welfare of friends and neighbors.

While friends and neighbors are obvious groups for both social comparisons and as generators of positive externalities such as through risk-sharing, there may be other groups that matter. Finding that people do not feel RD with respect to their friends and neighbors does not

19 For supportive evidence see Ravallion and Dearden (1988) (using data for Java, Indonesia). 20 Surveys of the lessons for economics from the "new psychology of happiness" can be found in Frey and Stutzer (2002) and Layard (2005). 
(of course) preclude RD with respect to some other comparison group. Could the presence of latent social comparators bias our inferences about friends and neighbors? Our estimates are only unbiased if the economic welfare of the omitted group is uncorrelated with that of friends and neighbors. Perceived deprivation compared to some omitted group will lead us to underestimate (overestimate) the welfare gains from having better-off friends and neighbors if the economic welfare of the omitted group is positively (negatively) correlated with the included groups. It seems unlikely that people with poor (rich) friends and neighbors would tend to compare themselves with rich (poor) omitted groups. If we discount that possibility, then we can still be confident that friends and neighbors are not a source of relative deprivation when we find a positive external effect.

The frame-of-reference effect

A potentially important but neglected concern about past empirical studies of selfassessed welfare is that different people may attach different meanings to the categories used in satisfaction or happiness questions. ${ }^{21}$ People answer such questions relative to their personal frame of reference (FOR), which depends on their own knowledge and experience. And this is likely to be correlated with characteristics of where they live, including mean income. It would seems reasonable to assume that people living in poor areas tend to have more limited knowledge and experience of the full range of levels of living found in the society as a whole. Someone living in a poor village who has only infrequently left the village and gone no further than the county town, will undoubtedly rate her economic welfare higher than someone with the same real income living in a city, who sees far greater affluence around her.

21 This is an instance of what is called differential item functioning (DIF) in the literature on educational testing where DIF exists if students with equal latent ability have different probabilities of giving a correct answer; for an overview of the history and methods of addressing DIF see Angoff (993). 
In these circumstances, heterogeneity in frames of reference will translate into corresponding differences in satisfaction with life. At given objective circumstances, the person living in the poor area will have higher perceived welfare because she simply does not know that many people live better than she does. Thus the regressions used in this literature would tend to reveal a negative coefficient on neighbors' mean income, even if there is no direct social comparison effect on utility, as postulated by RD theory. All the negative regression coefficient reflects is the difference in knowledge, which creates a systematic difference in the scale used to assess well-being. While the FOR effect would appear to be a serious concern about past tests for $\mathrm{RD}$, we can find no discussion in the literature of the likely biases. ${ }^{22}$

By using the respondent's self-assessed economic welfare instead of the objective value, $y$, for explaining $S W L$ we can reduce the bias, under the assumption that all subjective measures for a given respondent are subject to the same FOR effect. This is plausible since they are constrained by the same knowledge and experience. To see how this works, suppose that satisfaction with life would be $S W L^{*}$ if everyone had the same FOR, and (for the sake of the argument) let us assume that there is no $\mathrm{RD}$ effect, so that $S W L^{*}=\alpha+\beta y+\varepsilon$ with $\beta>0$ (and innovation error term $\varepsilon$ ). However, we do not observe $S W L^{*}$ but rather $S W L=S W L^{*}+\eta$ where $\eta$ is the FOR effect, which is negatively correlated with $y^{n}$ (for the reasons given above); in particular, assume that $\eta=\pi y^{n}, \pi<0$. Then $y^{n}$ will have a negative coefficient in the test equation for $\mathrm{RD}, \mathrm{SWL}=\alpha+\beta y+\pi y^{n}+\varepsilon$, even when there is no RD. Now include a subjective indicator of $y$, namely own-economic welfare $(O E W)$, which is subject to the same FOR effect,

22 Luttmer (2005) notes that the definition of 'happiness' might shift according to location but does not analyze the likely direction of bias, given that (as we argue here) the mean income of neighbors is likely to be correlated with knowledge about the range of objective levels of living in society as a whole. 
i.e., $O E W=\gamma y+\eta+v$ with an innovation error term $v$. The restriction that $\gamma \geq \beta$ seems

plausible; if anything the income effect would be lower for $S W L$. The test equation becomes:

$$
S W L=\alpha+\frac{\beta}{\gamma} O E W+\pi\left(1-\frac{\beta}{\gamma}\right) y^{n}+\varepsilon^{*}
$$

(where $\varepsilon^{*}=\varepsilon-\beta v / \gamma$ ). Thus the bias arising from heterogeneous FOR effects is attenuated using subjective economic welfare as the regressor, and it is eliminated entirely when the income effect for $S W L$ is the same as for $O E W(\beta=\gamma)$.

\section{Endogeneity of comparison-group welfare}

In common with other tests of RD theories in the literature, we treat our measures of the economic welfare of friends and neighbors as exogenous. ${ }^{23}$ This is unlikely to be as strong an assumption in this setting as in developed countries. Poor people in developing countries clearly do not have the same degree of freedom to choose their location — and hence their neighbors as in a developing country. In rural areas, poor people have typically lived in the same village or nearby for most of their lives. (We look at some evidence on this point for Malawi later.) It can also be argued that the externalities at issue stem from pre-existing relationships, which facilitate repeated interaction and trust. Exogeneity is a plausible assumption for risk sharing; people are unlikely to enter an informal risk-sharing arrangement with strangers. ${ }^{24}$ That is more contentious for the social comparisons than generate relative deprivation. If $\mathrm{RD}$ is an important factor then it may prompt people to change their friends and neighbors.

If poor people were free to choose their friends and neighbors, what would we expect to find in our data? With sufficient continuity, we can think of their problem as that of choosing

$23 \quad$ It is difficult to imagine defensible instrumental variables in this case; any variable that would influence one's choice of friends and neighbors would presumably also be a direct influence on one's overall welfare, invalidating the exclusion restriction required for identification.

$24 \quad$ There is evidence on this point in Fafchamps and Gubert (2005) who studied risk-sharing relationships amongst rural Filipinos. 
the comparison group's level of economic welfare. (This simplification is possible since, in our model, the only relevant parameter about a comparison group is its economic welfare.) Under regular conditions (sufficient to assure an interior optimum) the solution will entail setting to zero the derivative of the indirect utility function (as in equation 3) with respect to the comparison group's welfare. If (as we assume) satisfaction with life is a valid indicator of utility then we would not expect to find any partial correlation between $S W L$ and our measures of the economic welfare of the comparison groups, controlling for the other covariates (including $Y$ ). As we will see, this is not what we find in our data.

That is not a conclusive basis for dismissing concerns about endogenous choice of comparison-group welfare. We may still observe a correlation in the data because of the existence of unobserved variables that jointly influence both SWL and the choice of friends and neighbors. To explore the implications for our tests, we can (without loss of generality) take it to be the case that the unobserved variable raises utility. If that variable raises (lowers) the marginal utility of comparison-group welfare then it will increase (decrease) the optimal $y^{n}$, i.e., the latent variable will tend to be positively (negatively) correlated with $y^{n}$, implying that we over-estimate (under-estimate) the coefficient in a regression of SWL on $y^{n}$.

What direction of bias can we expect? Let us assume that equilibrium transfers attenuate (or at least do no accentuate) welfare disparities, i.e., friends and neighbors tend to be more (less) generous to people who have lower (higher) utility ceteris paribus. It can also be presumed that people in a risk-sharing group are better informed about each other's true welfare than is the researcher — in particular that they observe the latent factor in the model. Under these conditions, a latent utility-increasing factor will tend to reduce the marginal utility of $y^{n}$, and hence the optimal $y^{n}$, since friends and neighbors will be less generous in their transfers to those 
who are better endowed with that factor. Hence, $y^{n}$ will tend to be negatively correlated with the latent variable in our tests, and we will under-estimate the regression coefficient on $y^{n}$ when we treat it as exogenous.

This provides a further reason to suspect that past tests for RD in the literature are biased toward finding signs of $\mathrm{RD}$ - a negative effect of higher comparison-group economic welfare on measures of own-utility — in settings in which people are relatively free to choose their comparison group but there are also private transfers. In effect, the higher measured economic welfare of the comparison group is picking up a negative utility factor (unobserved to the researcher) that enhances the benefits from having a better-off comparison group, who can help compensate for the negative utility factor. In many developed-country settings where there is considerable geographic mobility, such as the US, this would seem a serious concern. Note that if we find that higher $y^{n}$ has a positive welfare effect when treating $y^{n}$ as exogenous then allowing for endogenous choice of $y^{n}$ would actually strengthen our conclusion that, on balance, people tend to gain from higher $y^{n}$, i.e., that $\mathrm{RD}$ is not the dominant social effect on welfare.

\section{Reporting biases in subjective data}

Another concern about our tests relates to our reliance on subjective assessments of welfare (whether the respondent's own welfare or that of friends and neighbors). These measures may not reflect well the true circumstances of either the respondent or her friends and neighbors. This is not a valid concern given that it is the subjective assessments that are of intrinsic interest in this context. Having better-off friends and neighbors is only going to matter to perceived well-being if one in fact perceives that the friends and neighbors are better off.

This argument assumes that people report accurately to the interviewer on their perceptions of both their own welfare and that of their friends and neighbors. More worrying for 
our tests is the possibility of systematic (non-random) reporting biases. If RD is a source of disutility then it may well influence the answers given to interviewers. Could this undermine our tests? It is instructive to consider a simple, yet seemingly plausible, model of that bias. Suppose that utility depends on own-economic welfare and comparison-group welfare and that RD matters, but to 'save face' the respondent hides the true RD from the interview. More precisely, assume that the responses are biased in amounts that are directly proportional to the difference between (true) own welfare and that of the comparison group; if the respondent feels poorer than her comparison group then she over-states her own economic welfare and/or under-states that of her comparison group. Evidently then the true parameters are positively-weighted linear combinations of the estimated parameters based on the reported data. ${ }^{25}$ The key implication is that (even though we do not know the bias parameters) if we find that both own-welfare and comparison-group welfare have positive coefficients then this must also be the case for the true parameters; reporting biases cannot be hiding a true RD effect when no such effect is observed empirically.

\section{Data and methods for Malawi}

We use the 2004 round of the Malawi Integrated Household Survey (MIHS). This is a comprehensive, nationally-representative survey of households administered between March 2004 and April 2005 by the Government of Malawi’s National Statistical Office with assistance from the World Bank, under the Living Standards Measurement Study. A two-stage stratified sample is based on the 1998 Malawi Population Census and is drawn from 564 enumerating

25 Suppose that $u=\alpha y+\beta y^{n}+\varepsilon$ for a measure of own-economic welfare $y$ and comparison-group welfare $y^{n}$. The reported values are related to the true values according to: $\hat{y}=y-\varphi_{1}\left(y-y^{n}\right)$ and $\hat{y}^{n}=y^{n}+\varphi_{2}\left(y-y^{n}\right)$ where $\varphi_{i} \in[0,1](i=1,2)$. Then $\alpha=a\left(1-\varphi_{1}\right)+b \varphi_{2}$ and $\beta=b\left(1-\varphi_{2}\right)+a \varphi_{1}$. 
areas (EA) ${ }^{26}$ In the first stage, the EAs were selected from each of the 30 strata (formed by districts split into urban and rural) with probability proportional to size. In the second stage, 20 households were randomly selected from each EA, giving a total sample of 11,280 households. MIHS collects data on household consumptions of a wide range of food and non-food items, detailed information about the socio-demographic composition of the interviewed households, labor status of the household members, health, educational achievements, various sources of household income including income in-kind, and individual wages. A section of the questionnaire asks the opinion of the household head about the household's standard of living, including questions about satisfaction with life and the economic ladder questions, which were added to the survey for the purpose of this study.

Our measure of overall welfare is provided by answers to the satisfaction with life (SWL) question: "Overall, how satisfied (content, happy) are you with your life? Are you (1) very unsatisfied; (2) unsatisfied; (3) neither unsatisfied nor satisfied; (4) satisfied; (5) very satisfied?” This was asked of the household head, but with explicit reference to the household's standard of living. The majority of the sample were not satisfied; $62.53 \%$ answered either (1) or (2) (24.35\% gave (1)). Slightly less than one quarter were satisfied; $18.33 \%$ gave (4) as their answer and $5.57 \%$ gave (5). (The remainder, $13.57 \%$, reported that they were neither unsatisfied nor satisfied.) These numbers indicate a much lower level of satisfaction with life than found in Western Europe where 80-90\% of the population report that they are satisfied with their lives when asked the same question in surveys, as compared to one quarter in Malawi (Delhey, 2004).

While $S W L$ is the natural choice for identifying a measure of utility, how should we measure economic welfare $(Y)$, as one argument of utility? We will use alternative objective and subjective measures. The most widely-used objective measure of economic welfare in

26 For a more detailed description of the sample design see National Statistics Office (2005). 
developing countries is consumption expenditure per person $(C)$ given by the total household expenditure, including spending on food (purchased and home-produced and food received as gifts), non-food items, estimated flow of services from consumer durable goods and actual or self-estimated rental cost of housing. ${ }^{27}$ Although this is a comprehensive consumption aggregate, there are well-known concerns about how well it reflects welfare, even when thought of as the narrower concept of 'economic welfare. ${ }^{, 28}$

A strict interpretation of our theoretical model would imply that $Y=y+\tau\left(y, y^{n}\right)=C$. However, our theoretical model simplifies reality in a number of respects, leaving concerns about how well consumption reflects perceptions of own economic status. The literature has pointed to concerns about (inter alia) the use of a market-price weighted aggregate of consumption and the calibration of deflators for demographic differences and cost-of-living differences. In that light, we cannot rule out the possibility that our results using consumption as the measure of $Y$ will be biased by correlations between the perceived economic welfare of friends and neighbors and the errors in measuring own welfare using consumption.

For these reasons, we also consider a measure of self-assessed economic welfare based on the own-economic welfare $(O E W)$ question in which respondents are asked: "Imagine six steps, where on the bottom, the first step, stand the poorest people, and on the highest step, the sixth, stand the rich (show a picture of the steps). On which step are you today?”

We also need measures of the economic welfare of relevant groups for social comparison or risk-sharing. People in geographic proximity to the respondent are an obvious source of comparators, co-insurers and help in other ways, such as finding employment. Using the

$27 \quad$ For details on how the consumption aggregate was formed see World Bank (2005b). 28 On the identification problem in consumer demand-based measures see Pollak (1991). Slesnick (1998) surveys alternative empirical approaches. Subjective welfare measures have been seen as a promising route to avoiding the identification problems in deriving a metric of welfare from observed demand behavior; for overviews of this approach see van Praag (1991) and Kapteyn (1994). 
geographic structure of the sample design we can estimate mean consumption of 'neighbors' using the survey data for the primary sampling unit containing each sampled household. The mean consumption of neighbors is estimated by the leave-out mean for the EA for each sampled household, i.e., the mean consumption of all sampled households in the respondent's EA, excluding the respondent.

As noted above, it is not clear that this provides a good measure of the economic welfare of neighbors. However, there is an additional source of information for studying social effects (that appears to have been largely ignored in the literature), namely to ask survey respondents about their comparison groups. We also use questions asking people about how they perceive the economic welfare of the two most obvious comparison groups: friends and neighbors. (Workplace comparisons are another possibility, but these are of limited relevance in a poor, largely rural, country such as Malawi.) It is left to the respondent to judge who are their friends and neighbors, and by what standard their economic status is to be judged. With regard to the respondent's friends we use the friends' economic welfare ( $F E W$ ) question: "Imagine six steps, where on the bottom, the first step, stand the poorest people, and on the highest step, the sixth, stand the rich: (show a picture of the steps). On which step are most of your friends today?” The same question is asked about neighbors' economic welfare (NEW).

Notice that consumption is measured post transfers and that it is reasonable to presume that $O E W$ also reflects post-transfer economic welfare. Thus, a strict interpretation of our model in section 2 would suggest that any effects on SWL of either mean consumption in the locality or of $F E W$ or $N E W$, controlling for our measures of own-economic welfare, could only reflect RD (since the transfer effect operates through own-economic welfare). That provides a seemingly 
strong test of RD theory: if the theory is right then we should find a negative conditional effect on SWL of our measure of the economic welfare of friends and neighbors.

However, this identifying assumption puts too much onus on our particular theoretical model. We can reasonably expect that the longer-term security provided by friends and neighbors would enhance one's satisfaction with life independently of current economic welfare. (That would also be the case if wealth gains to friends and neighbors facilitate investments in local public goods that take time to increase economic welfare.) So RD effects may still be present even if we find a non-negative effect of comparison-group welfare controlling for owneconomic welfare; the more robust conclusion one can draw is that RD may exist but is not dominant over the positive external effect.

Table 1 provides descriptive statistics (including for the control variables we will use in our regressions later); we also give an urban-rural breakdown. Note that on average, people tend to think that they are worse off economically than their friends and neighbors. Also note that in all dimensions (objective and subjective) living standards are higher in urban areas.

Two potentially important sources of positive external effects for poor people from better-off households are private transfers and employment, in the form of ganyu (as noted in the Introduction). Figure 1 shows how the total value of gifts given and gifts received (in cash and with imputed values for in-kind) vary with log consumption per person. (These are locallysmoothed scatter plots.) Gifts given (as a proportion of consumption) tend to rise with consumption, though with a sign of a U-shaped relationship in rural areas. Gifts received tend to fall in rural areas, but with signs of a u-shaped relationship in rural areas. Note that recorded receipts greatly exceed the value of gifts given (Table 1); this appears to be common in survey 
data. The net value of gifts received less gifts given represents about $5 \%$ of total consumption expenditure for the poorest households, and the ratio tends to fall with log consumption.

Recall that supplying casual piecework labor is known to be an important coping mechanism for the poor in Malawi. Figure 2 gives both the days of ganyu (over the last year) and income from ganyu as a proportion of total consumption expenditure, plotted against log consumption per person. It is clear that ganyu is a very important source of income for the poorest in both rural and urban areas; the poorest do about 80 days of ganyu per year, which accounts for a third or more of their consumption. The share of consumption accountable to ganyu falls sharply as living standards rise.

Another descriptive graph of interest is in Figure 3, which gives nonparametric regressions of the length of residence on log consumption per person. We see that there are markedly less signs of geographic mobility for the poor, in both urban and rural areas. The poorest households have lived in the same place for 15-20 years on average, while the least poor have done so for about 7 years. This does not suggest that people have been very active in choosing their neighbors by moving, though of course they may well be far more active in choosing their friends.

The two tests we perform on these data differ according to whether they use objective or subjective measures of economic welfare. Test 1 entails regressing $S W L$ on $\ln C$, the $\log$ of the leave-out mean consumption for the enumeration area (denoted $C^{n}$ ) and a vector of controls $(X)$, which attempt to also deal with systematic differences in the scales used for assessing welfare. (Table 1 lists the control variables.) This is similar to other tests found in the literature (cited above), except that we allow for an interaction effect between own consumption and neighbors' 
consumption. In specifying the econometric model, reported $S W L$ is interpreted as a qualitative indicator of continuous latent utility:

$$
u_{i}=\alpha \ln C_{i}+\beta \ln C_{i}^{n}+\gamma \ln C_{i} \cdot \ln C_{i}^{n}+\pi X_{i}+\varepsilon_{i}
$$

Assuming that the innovation error term $\varepsilon_{i}$ is normally distributed we use an Ordered Probit (OP) to estimate the parameters of (8).

Test 2 exploits the self-assessments of the economic welfare of friends and neighbors. This entails studying how $S W L$ varies jointly with $O E W, N E W$ and $F E W$. Initially we do not impose any parametric structure on the relationship. We then introduce the vector of regression controls, $X$, to allow for observable heterogeneity in household and geographic factors that might by biasing our tests. For this purpose, we switch to a parametric specification, again using an OP. The unobserved measure of utility now takes the form:

$$
\begin{aligned}
& u_{i}=\alpha O E W_{i}+\beta^{F} F E W_{i}+\beta^{N} N E W_{i}+\gamma^{F} O E W_{i} F E W_{i} \\
& +\gamma^{N} O E W_{i} N E W_{i}+\delta F E W_{i} N E W_{i}+\pi X_{i}+\varepsilon_{i}
\end{aligned}
$$

We also test an extended version of (9) in which the parameters on friend's and neighbor's economic welfare differ according to whether they are seen to be better or worse off than the household in question. This entails adding to (9), I(OEW $\left.<F E W_{i}\right) F E W_{i}$ and $I\left(O E W_{i}<F E W_{i}\right) O E W_{i} F E W_{i}$ (and similarly for $N E W$ ) where $I$ is a dummy variable taking the value one if $O E W_{i}<F E W_{i}$ and zero otherwise.

\section{Results}

Our results for Test 1 , based on equation (8) are found in Table 2 . We give two sets of results, depending on how we deal with geographic effects. In column (1) we use regional and urban-rural dummy variables, while in column (2) we use a complete set of dummy variables for 
the 221 'traditional authorities' (TA) (clusters of contiguous villages or urban localities); this is the maximum disaggregation we can have in allowing for geographic effects without losing identification.

Consistently with Case 3 in section 2, we find a negative interaction effect $(\hat{\gamma}<0)$. The effect is only significantly different from zero at the $10 \%$ level in specification (1), but becomes (highly) significant in specification (2).

The results of Test 1 indicate a positive effect of neighbors' consumption for the bulk of the data, though this declines as own-consumption rises. Using the more precise estimates from specification (2) in Table 2, we find that the neighborhood consumption effect is positive for $79 \%$ of data points (all those with log consumption under 10.21). However, SWL increases with own consumption over the entire range of consumptions found in the data.

There are a number of significant effects amongst the controls, though many of the parameter estimates are sensitive to allowing for a more complete accounting of the geographic effects, by including the TA dummy variables (which are clearly highly correlated with the other variables). Female headed households have lower $S W L$, agricultural households have higher $S W L$, although in specification (1) this effect is almost exactly offset by a negative effect of being a rural household. Many of the TA dummy variables had significant coefficients in (2).

On splitting the sample between rural and urban areas we find marked differences, as can be seen in Table 3. (We do not report the coefficients on $X$ to save space.) The external effect of neighbors' consumption and its negative interaction effect with own-consumption remain strong in rural areas, but they are only evident in urban areas when we include the geographic dummy variables (specification 2). In that case we find that the negative external effect dominates; indeed, the effect of neighbors' consumption is negative for the entire urban sample (i.e., log 
own consumption exceeds 8.04 for all sampled urban households). By interpretation, RD is the weaker social effect in rural areas, but the stronger one in urban areas.

Turning to Test 2, Table 4 gives mean SWL for OEW cross-tabbed against FEW and $N E W$; the lower panel is the cross-tab of friends' rank against neighbors' rank. We see that mean satisfaction with life rises with self-assessed economic welfare. And amongst those who consider themselves to be on either of the lowest two rungs of the economic welfare ladder, $S W L \underline{\text { rises }}$ with the perceived economic welfare of both friends and neighbors. For the (self-assessed) poor, these results are clearly more consistent with the theories that predict positive externalities echoing our previous results using objective measures of economic welfare. However, the gradient in mean SWL is markedly attenuated as one goes up the own-economic welfare ladder, with signs of a negative gradient with respect to neighbor's economic welfare emerging at the upper rungs. Relative deprivation appears to emerge at higher levels of own-economic welfare. We also see that amongst those who feel that they have poor neighbors, having well-off friends results in higher mean $S W L$. This gradient is more robust as one moves up the $N E W$ ladder.

An alternative non-parametric representation of the relationships in the data is found in Figure 4, which shows how the relationship between $S W L$ and $\ln C$ is shifted by changes in $N E W$ and FEW. The upper panel gives nonparametric regressions (again we use a locally-smoothed scatter plot) of $S W L$ on $\log$ consumption per capita $(\ln C)$ split according to friends' perceived economic welfare $(F E W)$; the lower panel gives the corresponding regression functions for $N E W$ and also provides the frequency distribution of $\ln C$. It can be seen that, over the bulk of the data, higher FEW or $N E W$ tends to come with higher $S W L$ at given $\ln C$. In both cases, the differences tend to be smaller amongst the consumption-poor. Looking at these figures, it is hard to find much support for the implications of RD theory. 
While these results are suggestive, there remains the question of whether they are robust to adding controls for observable heterogeneity. To do this we now switch to a simplified parametric representation of Test 2 . The key simplification is that we make the linearity assumption that the impact of a change from one rung to the next is constant. This assumption is clearly a simplification (for example, we see in Table 2 a larger change in mean SWL as one moves from rungs 1 to 2 than 3 to 4 ).

Table 5 provides our estimates of equation (9). (We dropped the term in FEW.NEW as it was highly insignificant.) Table 6 gives the derivatives and their standard errors; we give the derivatives w.r.t. $O E W$ evaluated at $F E W=N E W$. We find a negative interaction effect for both $N E W$ and $F E W$, though it is only statistically significant for FEW. The estimates imply that higher $O E W$ yields higher $S W L$ for all levels of $F E W$ and $N E W$. For specification (1), the impact on $S W L$ of higher FEW is positive for the lowest two rungs of $O E W$ (though only significant for the lowest rung) while for $N E W$ the effect is positive for the lowest four rungs (and significantly so for the lowest three). For (2), a significant negative effect emerges for FEW in the upper three rungs of $O E W$; however, there is no significant effect of $N E W$ in either direction at all levels of $O E W$. These results suggest that RD does emerge as a concern amongst middle and relatively well-off groups, at least for friends. However, we cannot rule out the possibility that this stems from a downward bias in our regression coefficient on the economic welfare of friends and neighbors when own-economic welfare reaches a relatively high level. This would be the case if people only become effectively free to choose their friends and neighbors at sufficiently high economic welfare, and if there are sources of utility that are unobserved by the researcher but observed by the people concerned, and voluntary redistribution tends to attenuate disparities in utility, as discussed in section 3.1. 
The rural-urban split of the main coefficients for Test 2 can be found in Table 7. Now we find no sign of an external effect (in either direction) in urban areas, though the effects found in Table 5 remain strong in rural areas.

We also checked if there are greater effects of $F E W$ and $N E W$ when a person felt worse off than her neighbors and friends, by adding the four interaction effects with the dummy variables described in the previous section. In specification (1), three of the four extra interaction effects had coefficients that were not significantly different from zero at the $10 \%$ level; the fourth, $I\left(O E W_{i}<N E W_{i}\right) N E W_{i} O E W_{i}$, had a coefficient of 0.037 with a standard error of 0.016 . In specification (2) none of the four interaction effects were significant at the $10 \%$ level. While there is some sign of a less strong negative interaction effect between $O E W$ and $N E W$ for those who feel poorer than their neighbors, the more parsimonious specification in (9) appears to provide an adequate representation of the data.

To help interpret our results, it is of interest to examine the contours of equation (9), as obtained by calculating the critical value of $O E W$ needed to compensate for differences in $F E W$ and $N E W$, while holding the expected value of utility constant (i.e., at $\varepsilon=0$ ). This can be interpreted as the utility-consistent poverty line in the space of economic welfare corresponding to a fixed reference utility level (the poverty line in the space of utility). When RD is the dominant social effect, the utility consistent poverty line will rise with comparison group economic welfare. However, this switches when the positive externality is dominant. Fixing the expected value of utility at $u^{*}$ one solves (9) for: ${ }^{29}$

\footnotetext{
29 We set $\delta=0$ consistently with our empirical results. Note that $O E W^{*}$ is a continuous variable,
} unlike $O E W$. 


$$
O E W_{i}^{*}=\frac{u^{*}-\beta^{F} F E W_{i}-\beta^{N} N E W_{i}-\pi X_{i}}{\alpha+\gamma^{F} F E W_{i}+\gamma^{N} N E W_{i}}
$$

Table 8 provides the values of $O E W^{*}$ at mean points for $X$ and for two reference utility levels defined by the middle two cut-off points from the OP from Table 4, specification (1). The proportion of the population reporting that they are below the lower of these two cut-off points (i.e., that they are either 'very unsatisfied' or 'unsatisfied') corresponds closely to prevailing estimates of the poverty rate for Malawi.

Focusing first on panel (a) in Table 8, we find that for $u^{*}$ at the estimated cut-off point below which one is either 'very unsatisfied' or 'unsatisfied,' the value of $O E W^{*}$ tends to fall as FEW rises (at given $N E W$ ) and similarly $O E W^{*}$ falls as $N E W$ rises (at given $F E W$ ). This pattern reflects the positive utility gains from having better off friends and neighbors. However, the pattern reverses when we shift to the higher reference utility level (panel b), when the RD effect kicks in. Then the poverty lines in the space of perceived economic welfare start to look like relative poverty lines. However, note that in all cases in Table 8, the gradients in $O E W^{*}$ are small; to the nearest ladder rung, the poverty line is at $O E W^{*}=3$ for $80 \%$ of cases in panel (a) and it is $O E W^{*}=4$ for $80 \%$ of cases in panel (b).

\section{Conclusions}

Relative deprivation is seen to stem from social comparisons that generate negative externalities from economic gains to friends and neighbors. Other theories point instead to positive external effects arising from institutions for risk-sharing, the provision of local-public goods, local employment opportunities or productivity-enhancing spillovers. These arguments predict that it is an asset to have well-off friends and neighbors. 
We have identified conditions under which relative deprivation will dominate the gains from risk sharing or collective provisioning. If full risk-sharing is attainable then the positive effect of an increase in the community's mean income will always dominate relative deprivation. With partial risk sharing (constrained by the need to avoid defection from the co-insurance group) the outcome is less clear. In a special case of our general model, we show that the positive external effect will tend to be the dominant factor for the poor, while relative deprivation will emerge as a concern at high incomes.

In marked contrast to past empirical work for developed countries, our empirical results do not suggest that perceived economic disparities relative to friends and neighbors are a welfare-relevant concern for most people in Malawi, and certainly not for the poor. Neither objective nor subjective measures of economic welfare reveal any sign of relative deprivation effects for poor people. Indeed, most specifications tested indicate significant positive external effects for the bulk of the data, though these effects are largely confined to rural areas. We cannot rule out biases in our tests arising from systematic reporting errors and endogenous choice of friends and neighbors, though we have pointed to seemingly plausible assumptions under which correcting for these biases would not alter our main qualitative conclusion that having well-off friends and neighbors in this setting is generally seen as an asset not a liability. We find signs of a negative interaction effect between friends' economic welfare and own owneconomic welfare in rural areas, such that relative deprivation does emerge as a concern amongst the relatively well-off. Within the boundaries of this low-income country, we find economically well-off people who essentially care about relative position, side-by-side with a large number of poorer people (by far the majority) who appears to care far more about their absolute levels of living. 
These findings offer a welfarist explanation as to why absolute poverty considerations have dominated development-policy discussions. We find little support for the idea implied by relative deprivation theory of a poverty line which rises with the mean income of the comparison group. Indeed, our results suggest the opposite property; for the bulk of the households in our sample, the utility-consistent poverty line would actually fall as the comparison-group income increases (though our quantitative results do not suggest much gradient). However, on splitting our sample between urban and rural areas, our results are consistent with the idea that relative deprivation will be more important as the economy becomes more urbanized.

There are also some potential insights from our results for understanding the causes of rural under-development. The dominance of the positive externality for the rural poor implies that there will be too little incentive to take actions that increase one's own income, given the spillover effect to others. In other words, there will be too much poverty from an efficiency point of view. The fact that we find signs that relative deprivation becomes the most important social effect amongst the upper economic stratum also suggests the possibility that the incentive effect reverses amongst the relatively well-off. The distributional implications will depend on the extent to which economic gains to the rich spillover to benefit the poor. While we cannot rule out the possibility that poor people in Malawi have rich friends and neighbors, it does not seem very likely as a general rule, if only because the rich would see the gains from isolating themselves physically or socially from the poor. (Urban enclaves may well be part of that process.) If the bulk of the positive external effect from better-off friends and neighbors is amongst poor, middle-income and predominantly rural groups, while the relative deprivation effect is largely confined amongst urban elites, then we will have a situation in which there will also be too much inequality from the point of view of aggregate efficiency. 


\section{References}

Akerlof, George A., and Janet Yellen (1990) "The Fair Wage-Effort Hypothesis and Unemployment," Quarterly Journal of Economics 105: 255-284.

Alpizar, Francisco, Fredrik Carlsson and Olof Johansson-Stenman (2005) "How Much Do We Care About Absolute versus Relative Income and Consumption?” Journal of Economic Behavior and Organization 56: 405-421.

Angoff, William H., (1993) “Perspectives on Differential Item Functioning Methodology,” in Paul Holland and Howard Wainer (eds) Differential Item Functioning, Lawrence Erlbaum Associates.

Becker, Gary S. (1974) “A Theory of Social Interactions,” Journal of Political Economy 82: 1063-1093.

Blanchflower, D. and A. Oswald (2004) "Well-Being over Time in Britain and the U.S.A." Journal of Public Economics 88: 1359-1386.

Bowles, Samuel and Herbert Gintis (2002) "Social Capital and Community Governance," Economic Journal 112: F419-F439.

Clark, Andrew E., and Andrew J. Oswald (1996) "Satisfaction and Comparison Income," Journal of Public Economics 61: 359-381.

Coate, Stephen and Martin Ravallion (1993) "Reciprocity Without Commitment:

Characterization and Performance of Informal Insurance Arrangements," Journal of Development Economics, 40: 1-25.

Cox, Donald, Bruce Hansen and Emmanuel Jimenez (2004), "How Responsive Are Private Transfers to Income? Evidence from a Laissez-Faire Economy,” Journal of Public Economics 88: 2193-2219.

Delhey, Ian (2004), “Life Satisfaction in an Enlarged Europe,” European Foundation for the Improvement of Living and Working Conditions, Dublin, Ireland.

Easterlin, Richard A. (1974), "Does Economic Growth Improve the Human Lot? Some Empirical Evidence," in P.A. David and W.R. Melvin (eds) Nations and Households in Economic Growth, Palo Alto: Stanford University Press.

(1995) "Will Raising the Incomes of all Increase the Happiness of all?" Journal of Economic Behavior and Organization 27: 35-47. 
Ellis, Frank, Milton Kutengule and Alfred Nyasulu (2003) "Livelihoods and Rural Poverty Reduction in Malawi,” World Development 31(9): 1495-1510.

Englund, Harri (1999) "The Self in Self-Interest: Land, Labour and Temporalities in Malawi's Agrarian Change,” Africa: Journal of the International African Institute 69(1): 137-159.

Ferrer-i-Carbonell A. (2005). "Income and well-being: An empirical analysis of the comparison income effect, Journal of Public Economics, 89: 997-1019.

Fafchamps, Marcel and Flore Gubert (2005), "The Formation of Risk Sharing Networks,” mimeo, Department of Economics, Oxford University.

Fafchamps, Marcel and Susan Lund (2003), "Risk-Sharing Networks in Rural Philippines," Journal of Development Economics 71(2): 261-87.

Frank, Robert H. (1985), "The Demand for Unobservable and Other Nonpositional Goods," American Economic Review 75(1): 101-16. (1997), “The Frame of Reference as a Public Good”, Economic Journal 107: 1832-1847.

Frey, Bruno and A. Stutzer (2002), “Can Economists Learn from Happiness Research?” Journal of Economic Literature 40(2): 402-435.

Jalan, Jyotsna and Martin Ravallion (2002) “Geographic Poverty Traps? A Micro Model of Consumption Growth in Rural China,” Journal of Applied Econometrics 17(4): 329-346.

Kahneman, Daniel and Carol Varey (1991) "Notes on the Psychology of Utility," in Jon Elster and John Roemer (eds) Interpersonal Comparisons of Well-Being, Cambridge: Cambridge University Press.

Kapteyn, Arie, (1994), “The Measurement of Household Cost Functions. Revealed Preference Versus Subjective Measures,” Journal of Population Economics 7: 333-350.

Layard, Richard (2005) Happiness: Lessons from a New Science. New York: Penguin Press. Ligon, Ethan, Jonathan Thomas and Tim Worrall, (2002) “Informal Insurance Arrangements with Limited Commitment: Theory and Evidence from Village Economies, Review of Economic Studies 69(1): 209-44.

Luttmer, Erzo F.P. (2005), “Neighbors as Negatives: Relative Earnings and Well-Being,” Quarterly Journal of Economics 120(3): 963-1002. 
McBride, M (2001) "Relative Income Effects on Subjective Well-Being in the Cross-Section.” Journal of Economic Behavior and Organization 45: 251-278.

Maitra, Pushkar and Ranjan Ray (2003), "The Effect of Transfers on Household Expenditure Patterns and Poverty in South Africa," Journal of Development Economics 71: 23-49.

Mansuri, Ghazala and Vijayendra Rao. 2004. Community-Based and -Driven Development. World Bank Research Observer 19(1): 1-40.

Morduch, Jonathan (1999), "Between the State and the Market: Can Informal Insurance Patch the Safety Net?” World Bank Research Observer 14(2): 187-202.

Mtika, Mike Mathambo (2001), "The AIDS Epidemic in Malawi and its Threat to Household Food Security,” Human Organization 60(2): 178-188.

Murgai, Rinku, Paul Winters, Elisabeth Sadoulet and Alain de Janvrey (2002), "Localized and Incomplete Mutual Insurance,” Journal of Development Economics 67: 245-274.

Narayan, Deepa and Patti Petesch (eds) (2002), Voices of the Poor from Many Lands, Washington DC: World Bank.

National Economic Council (2000), Profile of Poverty in Malawi, 1998: Poverty Analysis of the Malawi Integrated Household Survey. Lilongwe: National Economic Council, Government of Malawi.

National Statistics Office (2005), "Malawi Second Integrated Household Survey (IHS-2) 20042005 Basic Information Document,” National Statistics Office, Government of Malawi.

Oswald, Andrew J., (1997) “Happiness and Economic Performance”, Economic Journal 107: 1815-1831.

Peters, Pauline E. (2004), “The Differential Effects on Rural Income and Poverty of a decade of Radical Change in Malawi, 1986-97,” BASIS Collaborative Research Support Program, University of Wisconsin-Madison.

Pollak, Robert, (1991) "Welfare Comparisons and Situation Comparisons”, Journal of Econometrics 50: 31-48.

Pradhan, Menno and Martin Ravallion (2000), “Measuring Poverty Using Qualitative Perceptions of Consumption Adequacy," Review of Economics and Statistics, 82(3): 462-471.

Rao, Vijayendra (2001), "Poverty and Public Celebrations in Rural India,” Annals of the American Academy of Political and Social Science, 573: 85-104. 
Ravallion, Martin (1998), Poverty Lines in Theory and Practice, LSMS Paper 133, Washington DC, World Bank.

(2005) "Poverty Lines," in The New Palgrave Dictionary of Economics, 2nd edition, Larry Blume and Steven Durlauf (eds) London: Palgrave Macmillan.

Ravallion, Martin and Lorraine Dearden, (1988), “Social Security in a 'Moral Economy': An Empirical Analysis for Java”, Review of Economics and Statistics, 70: 36-45.

Ravallion, Martin and Michael Lokshin, (2002), "Self-assessed Economic Welfare in Russia." European Economic Review 46: 1453-1473.

Ribar, David (2005), “The Persistence of Financial Strains among Low-Income Families: An Analysis of Multiple Indicators,” mimeo, Department of Economics, George Washington University.

Runciman, W.G., (1966), Relative Deprivation and Social Justice. Routledge and Kegan Paul.

Schechter, Laura, (2005), “Theft, Gift-Giving and Trustworthiness: Honesty is its Own Reward in Rural Paraguay,” mimeo, Department of Agricultural and Applied Economics, University of Wisconsin at Madison.

Sen, Amartya K., (1983), "Poor, Relatively Speaking.” Oxford Economic Papers 35: 153-169.

Senik, Caludia, (2004), "When Information Dominates Comparison: Learning from Russian Subjective Panel Data,” Journal of Public Economics 88: 20099-2123.

Slesnick, Daniel T., (1998), “Empirical Approaches to Measuring Welfare”, Journal of Economic Literature, 36: 2108-2165.

Solnick, Sara and David Hemenway (1998). "Is More Always Better? A Survey on Positional Concerns”. Journal of Economic Behavior \& Organization 37: 373-83.

Townsend, Peter, (1979), Poverty in the United Kingdom, Harmondsworth, Middlesex: Penguin Books.

van de Stadt, Huib, Arie Kapteyn, and Sara van de Geer (1985) "The Relativity of Utility: Evidence from Panel Data”, Review of Economics and Statistics 67: 179-187. van Praag, Bernard (1991) "Ordinal and Cardinal Utility: An Integration of the Two Dimensions of the Welfare Concept,” Journal of Econometrics 50(1-2): 69-89.

Walker, Iain and Heather Smith (eds) (2001), Relative Deprivation: Specification, Development, and Integration, Cambridge: Cambridge University Press. 
Whiteside, Martin (2000) "Ganyu Labor in Malawi and its Implications for Livelihood Security Interventions: An Analysis of Recent Literature and Implications for Poverty Reduction,” Agricultural Research and Extension Network Paper No.99, Overseas Development Institute, London.

World Bank (2005a) World Development Report: Equity and Development, New York: Oxford University Press.

(2005b) "Note on Construction of Expenditure Aggregate and Poverty Lines for IHS2,” mimeo, Development Economic Research Group, Washington, DC. 
Table 1: Summary statistics

\begin{tabular}{|c|c|c|c|c|c|c|}
\hline & \multicolumn{2}{|c|}{ National } & \multicolumn{2}{|c|}{ Rural } & \multicolumn{2}{|c|}{ Urban } \\
\hline & Mean & Std. dev. & Mean & Std. dev. & Mean & Std. dev. \\
\hline Satisfaction with live (SWL) & 2.426 & 1.197 & 2.348 & 1.161 & 2.754 & 1.287 \\
\hline Log per capita expenditure & 9.794 & 0.690 & 9.690 & 0.621 & 10.235 & 0.785 \\
\hline Log leave-out mean for EA & 9.954 & 0.453 & 9.839 & 0.350 & 10.444 & 0.506 \\
\hline Own economic welfare $(O E W)$ & 1.754 & 0.811 & 1.670 & 0.764 & 2.109 & 0.903 \\
\hline Friends’ economic welfare (FEW) & 2.184 & 1.064 & 2.088 & 1.033 & 2.588 & 1.095 \\
\hline Neighbors' economic welfare (NEW) & 1.929 & 0.919 & 1.820 & 0.857 & 2.392 & 1.025 \\
\hline \multicolumn{7}{|l|}{ Transfers and ganyu } \\
\hline Gifts given as a share of total C & 0.013 & 0.036 & 0.012 & 0.034 & 0.020 & 0.039 \\
\hline Gifts received as a share of total $C$ & 0.025 & 0.072 & 0.024 & 0.066 & 0.028 & 0.093 \\
\hline Total days of ganyu & 33.243 & 70.514 & 35.152 & 70.561 & 25.182 & 69.758 \\
\hline Ganyu earnings as a share of $C$ & 0.066 & 0.881 & 0.059 & 0.368 & 0.097 & 1.866 \\
\hline \multicolumn{7}{|l|}{ Household demographics } \\
\hline Household size & 4.545 & 2.335 & 4.569 & 2.320 & 4.442 & 2.394 \\
\hline Share of children & 0.392 & 0.002 & 0.401 & 0.002 & 0.352 & 0.005 \\
\hline Share of elderly & 0.062 & 0.002 & 0.069 & 0.002 & 0.031 & 0.003 \\
\hline Share of adult women & 0.275 & 0.002 & 0.275 & 0.002 & 0.275 & 0.004 \\
\hline Share of adult men & 0.275 & 0.002 & 0.275 & 0.002 & 0.275 & 0.004 \\
\hline Share of employed & 0.603 & 0.003 & 0.628 & 0.003 & 0.498 & 0.006 \\
\hline Female headed household & 0.230 & 0.004 & 0.241 & 0.004 & 0.181 & 0.008 \\
\hline Head's age & 42.448 & 16.357 & 43.378 & 16.727 & 38.520 & 14.033 \\
\hline Agricultural household & 0.890 & 0.003 & 0.966 & 0.002 & 0.567 & 0.011 \\
\hline Household has an enterprise & 0.312 & 0.004 & 0.289 & 0.005 & 0.410 & 0.011 \\
\hline Household has an unemployed person & 0.015 & 0.001 & 0.004 & 0.001 & 0.059 & 0.005 \\
\hline \multicolumn{7}{|l|}{ Education of the head } \\
\hline Illiterate & 0.269 & 0.004 & 0.302 & 0.005 & 0.130 & 0.007 \\
\hline Junior Primary & 0.230 & 0.004 & 0.256 & 0.005 & 0.122 & 0.007 \\
\hline Senior Primary & 0.325 & 0.004 & 0.323 & 0.005 & 0.334 & 0.010 \\
\hline Junior Secondary & 0.017 & 0.001 & 0.016 & 0.001 & 0.022 & 0.003 \\
\hline Senior Secondary & 0.142 & 0.003 & 0.095 & 0.003 & 0.340 & 0.010 \\
\hline University degree & 0.016 & 0.001 & 0.008 & 0.001 & 0.052 & 0.005 \\
\hline \multicolumn{7}{|l|}{ Regions } \\
\hline Karonga & 0.043 & 0.002 & 0.042 & 0.002 & 0.047 & 0.005 \\
\hline Mzuzu & 0.106 & 0.003 & 0.103 & 0.003 & 0.121 & 0.007 \\
\hline Kasungu & 0.107 & 0.003 & 0.119 & 0.003 & 0.056 & 0.005 \\
\hline Salima & 0.048 & 0.002 & 0.053 & 0.002 & 0.028 & 0.004 \\
\hline Lilongwe (capital) & 0.229 & 0.004 & 0.219 & 0.004 & 0.270 & 0.010 \\
\hline Machinga & 0.191 & 0.004 & 0.198 & 0.004 & 0.165 & 0.008 \\
\hline Blantyre & 0.212 & 0.004 & 0.195 & 0.004 & 0.286 & 0.010 \\
\hline Ngabu & 0.064 & 0.002 & 0.073 & 0.003 & 0.028 & 0.004 \\
\hline \multicolumn{7}{|l|}{ Type of settlement } \\
\hline Major Urban areas & 0.128 & 0.003 & 0.000 & 0.000 & 0.667 & 0.010 \\
\hline Boma/Large Urban areas & 0.018 & 0.001 & 0.000 & 0.000 & 0.092 & 0.006 \\
\hline Small Urban areas & 0.046 & 0.002 & 0.000 & 0.000 & 0.241 & 0.009 \\
\hline Rural areas & 0.809 & 0.004 & 1.000 & 0.000 & 0.000 & 0.000 \\
\hline Number of observations & \multicolumn{2}{|c|}{11,219} & \multicolumn{2}{|c|}{9,071} & \multicolumn{2}{|c|}{2,148} \\
\hline
\end{tabular}


Table 2: Test 1: Ordered probits for satisfaction with life based on equation (8)

\begin{tabular}{|c|c|c|c|c|}
\hline & \multicolumn{2}{|c|}{ (1) } & \multicolumn{2}{|c|}{ (2) } \\
\hline & Coefficient & Std. error & Coefficient & Std. error \\
\hline Log real consumption per person $(\log C)$ & $0.702 * *$ & 0.250 & $1.822^{* * *}$ & 0.338 \\
\hline Log leave-out mean $C$ in the locality & 0.361 & 0.249 & $1.480 * * *$ & 0.331 \\
\hline Interaction of $\log C$ with leave-out mean & $-0.042^{*}$ & 0.025 & $-0.145^{* * *}$ & 0.033 \\
\hline Household size $(N)$ & $0.051 * *$ & 0.017 & $0.077 * * *$ & 0.018 \\
\hline$N^{2}$ & $-0.002 *$ & 0.001 & $-0.003^{*}$ & 0.001 \\
\hline Share of children & 0.116 & 0.077 & $-0.138 *$ & 0.081 \\
\hline Share of elderly & 0.057 & 0.080 & -0.023 & 0.084 \\
\hline Share of adult women & 0.081 & 0.071 & -0.035 & 0.074 \\
\hline Share of adult men & \multicolumn{4}{|c|}{ Reference category } \\
\hline Share of employed & $0.122 *$ & 0.054 & $-0.126^{*}$ & 0.059 \\
\hline Female household head & $-0.093 * *$ & 0.029 & $-0.081^{* *}$ & 0.030 \\
\hline Age of Household Head & 0.000 & 0.001 & 0.000 & 0.001 \\
\hline Agricultural household & $0.197 * * *$ & 0.040 & $0.080 *$ & 0.045 \\
\hline Household has an enterprise & 0.014 & 0.022 & $0.068 * *$ & 0.024 \\
\hline Household has an unemployed person & 0.054 & 0.086 & -0.133 & 0.093 \\
\hline \multicolumn{5}{|l|}{ Education of the head } \\
\hline Pre-school & $-0.156^{*}$ & 0.092 & -0.047 & 0.097 \\
\hline Junior Primary & -0.069 & 0.091 & 0.032 & 0.096 \\
\hline Senior Primary & -0.015 & 0.089 & 0.089 & 0.095 \\
\hline Junior Secondary & -0.117 & 0.115 & -0.068 & 0.121 \\
\hline Senior Secondary & -0.013 & 0.088 & 0.105 & 0.094 \\
\hline University & \multicolumn{4}{|c|}{ Reference category } \\
\hline Lilongwe (Capital City) & \multicolumn{4}{|c|}{ Reference category } \\
\hline Karonga & $0.251 * * *$ & 0.056 & n.a. & \\
\hline Mzuzu & $0.120 * *$ & 0.038 & n.a. & \\
\hline Kasungu & $-0.198 * * *$ & 0.038 & n.a. & \\
\hline Salima & $-0.145^{* *}$ & 0.053 & n.a. & \\
\hline Machinga & $0.164 * * *$ & 0.032 & n.a. & \\
\hline Blantyre & $-0.132 * * *$ & 0.031 & n.a. & \\
\hline Ngabu & 0.028 & 0.047 & n.a. & \\
\hline Major Urban areas & \multicolumn{4}{|c|}{ Reference category } \\
\hline Boma/Large Urban areas & $0.366^{* * *}$ & 0.083 & n.a. & \\
\hline Small Urban areas & $0.185 * *$ & 0.058 & n.a. & \\
\hline Rural areas & $-0.195 * * *$ & 0.042 & n.a. & \\
\hline Traditional authorities dummy variables? & NO & & YES & \\
\hline Cut 1 & 5.898* & 2.468 & $17.132 * * *$ & 3.380 \\
\hline Cut 2 & $6.949 * *$ & 2.468 & $18.418^{* * *}$ & 3.381 \\
\hline Cut 3 & $7.355^{* *}$ & 2.468 & $18.905^{* * *}$ & 3.381 \\
\hline Cut 4 & $8.266^{* * *}$ & 2.468 & $19.952^{* * *}$ & 3.381 \\
\hline Pseudo-R2 & \multicolumn{2}{|c|}{0.020} & \multicolumn{2}{|c|}{0.138} \\
\hline
\end{tabular}

Note: ${ }^{*}$ is significant at $10 \%$ level; ${ }^{* *}$ at $5 \%$ level; ${ }^{* * *}$ at $1 \%$ level. $\mathrm{N}=11,219$. 
Table 3: Rural-urban split for Test 1

\begin{tabular}{|c|c|c|c|c|c|c|c|c|}
\hline & \multicolumn{4}{|c|}{ Rural } & \multicolumn{4}{|c|}{ Urban } \\
\hline & \multicolumn{2}{|c|}{ (1) } & \multicolumn{2}{|c|}{ (2) } & \multicolumn{2}{|c|}{ (1) } & \multicolumn{2}{|c|}{ (2) } \\
\hline & Coeff. & $\begin{array}{l}\text { Std. } \\
\text { error }\end{array}$ & Coeff. & $\begin{array}{l}\text { Std. } \\
\text { error }\end{array}$ & Coeff. & $\begin{array}{l}\text { Std. } \\
\text { error }\end{array}$ & Coeff. & $\begin{array}{l}\text { Std. } \\
\text { error }\end{array}$ \\
\hline $\log C$ & $2.057 * * *$ & 0.433 & $2.540 * * *$ & 0.485 & -0.322 & 0.559 & $2.142^{* *}$ & 0.731 \\
\hline $\begin{array}{l}\text { Log leave- } \\
\text { out mean }\end{array}$ & $1.717 * * *$ & 0.425 & $2.206 * * *$ & 0.482 & -0.812 & 0.553 & $1.327 *$ & 0.724 \\
\hline Interaction & $-0.181^{* * *}$ & 0.044 & $-0.220 * * *$ & 0.049 & 0.061 & 0.053 & $-0.165^{*}$ & 0.069 \\
\hline $\mathrm{N}$ & 9,071 & & 9,071 & & 2,148 & & 2,148 & \\
\hline Pseudo-R2 & 0.013 & & 0.121 & & 0.060 & & 0.189 & \\
\hline
\end{tabular}

Note: Controls included, as in Table 2.

Table 4: Average satisfaction with life by self-rated own economic welfare and assessed welfare of friends and neighbors (Test 2; non-parametric)

\begin{tabular}{|c|c|c|c|c|c|c|c|}
\hline \multirow{2}{*}{\multicolumn{2}{|c|}{ Mean $S W L$}} & \multicolumn{5}{|c|}{ Own economic ranking $(O E W)$} & \multirow[b]{2}{*}{ Tota } \\
\hline & & 1 (poorest) & 2 & 3 & 4 & 5 & \\
\hline \multirow{5}{*}{ 施 } & 1 (poorest) & 2.057 & 2.367 & 3.071 & 2.933 & n.a. & 2.153 \\
\hline & 2 & 2.176 & 2.600 & 2.827 & 3.022 & n.a. & 2.465 \\
\hline & 3 & 2.130 & 2.548 & 2.945 & 2.932 & n.a. & 2.567 \\
\hline & 4 & 2.362 & 2.539 & 2.910 & 3.203 & n.a. & 2.710 \\
\hline & 5 & 2.405 & 2.569 & 2.911 & 3.205 & 3.348 & 2.746 \\
\hline \multirow{6}{*}{ 竞 } & 1 (poorest) & 2.068 & 2.419 & 2.894 & 3.524 & n.a. & 2.217 \\
\hline & 2 & 2.143 & 2.590 & 2.891 & 2.860 & n.a. & 2.468 \\
\hline & 3 & 2.348 & 2.609 & 2.770 & 3.174 & 3.538 & 2.627 \\
\hline & 4 & 2.556 & 2.649 & 3.125 & 2.967 & n.a. & 2.875 \\
\hline & 5 & 2.282 & 2.600 & 3.200 & 3.273 & n.a. & 2.833 \\
\hline & Total & 2.124 & 2.550 & 2.905 & 3.076 & 3.441 & 2.426 \\
\hline \multicolumn{8}{|c|}{ Economic ranking of neighbors (NEW) } \\
\hline \multirow{6}{*}{ 串密 } & 1 (poorest) & 2.125 & 2.139 & 2.453 & 2.800 & 2.579 & 2.153 \\
\hline & 2 & 2.279 & 2.491 & 2.651 & 2.794 & 2.645 & 2.465 \\
\hline & 3 & 2.402 & 2.552 & 2.566 & 3.088 & 2.714 & 2.567 \\
\hline & 4 & 2.514 & 2.742 & 2.714 & 2.761 & 2.838 & 2.710 \\
\hline & 5 & 2.481 & 2.633 & 2.797 & 2.816 & 3.137 & 2.746 \\
\hline & Total & 2.217 & 2.468 & 2.627 & 2.875 & 2.833 & 2.426 \\
\hline
\end{tabular}

Note: SWL is self-assessed on a scale from 1 (very unsatisfied) to 5 (very satisfied). Means not reported when less that 12 sample points. 
Table 5: Test 2: Ordered probits for satisfaction with life based on equation (9)

\begin{tabular}{|c|c|c|c|c|}
\hline & \multicolumn{2}{|c|}{ (1) } & \multicolumn{2}{|c|}{ (2) } \\
\hline & Coefficient & Std. error & Coefficient & Std. error \\
\hline Own economic welfare $(O E W)$ & $0.424 * * *$ & 0.035 & $0.582 * * *$ & 0.038 \\
\hline Friends’ economic welfare (FEW) & $0.076 * *$ & 0.025 & $0.102^{* * *}$ & 0.027 \\
\hline Neighbors’ economic welfare ( $N E W$ ) & $0.110^{* * *}$ & 0.031 & 0.041 & 0.033 \\
\hline OEW.FEW & $-0.032 * *$ & 0.012 & $-0.055 * * *$ & 0.013 \\
\hline OEW.NEW & -0.023 & 0.014 & -0.016 & 0.015 \\
\hline Household size $(N)$ & -0.020 & 0.017 & -0.026 & 0.017 \\
\hline$N^{2}$ & 0.000 & 0.001 & 0.001 & 0.001 \\
\hline Share of children & 0.021 & 0.076 & $-0.235^{* *}$ & 0.080 \\
\hline Share of elderly & 0.029 & 0.080 & -0.056 & 0.084 \\
\hline Share of adult women & 0.045 & 0.071 & -0.077 & 0.074 \\
\hline \multicolumn{5}{|l|}{ Share of adult men (reference) } \\
\hline Share of employed & $0.129 *$ & 0.054 & -0.081 & 0.059 \\
\hline Female household head & $-0.092 * *$ & 0.029 & $-0.062 *$ & 0.030 \\
\hline Age of Household Head & 0.000 & 0.001 & -0.000 & 0.001 \\
\hline Agricultural household & $0.214 * * *$ & 0.040 & 0.071 & 0.045 \\
\hline Household has an enterprise & 0.020 & 0.022 & $0.065 * *$ & 0.024 \\
\hline Household has an unemployed person & 0.071 & 0.086 & -0.114 & 0.093 \\
\hline \multicolumn{5}{|l|}{ Education of the head } \\
\hline Pre-school & -0.022 & 0.087 & 0.107 & 0.096 \\
\hline Junior Primary & 0.053 & 0.086 & $0.177^{*}$ & 0.095 \\
\hline Senior Primary & 0.082 & 0.084 & $0.206^{*}$ & 0.093 \\
\hline Junior Secondary & -0.020 & 0.112 & 0.046 & 0.120 \\
\hline Senior Secondary & 0.026 & 0.085 & $0.173^{*}$ & 0.093 \\
\hline \multicolumn{5}{|l|}{ University (reference) } \\
\hline \multicolumn{5}{|l|}{ Lilongwe (Capital City) (reference) } \\
\hline Karonga & $0.185^{* * *}$ & 0.056 & n.a. & \\
\hline Mzuzu & 0.001 & 0.038 & n.a. & \\
\hline Kasungu & $-0.233 * * *$ & 0.038 & n.a. & \\
\hline Salima & -0.055 & 0.054 & n.a. & \\
\hline Machinga & $0.084 * *$ & 0.031 & n.a. & \\
\hline Blantyre & $-0.130 * * *$ & 0.031 & n.a. & \\
\hline Ngabu & $0.108^{*}$ & 0.046 & n.a. & \\
\hline Major Urban areas (reference) & n.a. & & & \\
\hline Boma/Large Urban areas & $0.412 * * *$ & 0.083 & n.a. & \\
\hline Small Urban areas & $0.197 * * *$ & 0.058 & n.a. & \\
\hline Rural areas & $-0.163 * * *$ & 0.039 & n.a. & \\
\hline Traditional authorities dummy variables? & NO & & YES & \\
\hline Cut1 & $0.260 *$ & 0.122 & $17.132 * * *$ & 3.380 \\
\hline Cut2 & $1.331 * * *$ & 0.122 & $18.418 * * *$ & 3.381 \\
\hline Cut3 & $1.748^{* * *}$ & 0.123 & $18.905^{* * *}$ & 3.381 \\
\hline Cut4 & $2.682 * * *$ & 0.124 & $19.952 * * *$ & 3.381 \\
\hline Pseudo-R2 & & & 0.1 & \\
\hline
\end{tabular}

Note: ${ }^{*}$ is significant at $10 \%$ level; ${ }^{* *}$ at $5 \%$ level; ${ }^{* * *}$ at $1 \%$ level. $\mathrm{N}=11,219$. 
Table 6: Derivatives of equation (9) using self-assessed own economic welfare

\begin{tabular}{|c|c|c|c|c|c|c|}
\hline \multirow[t]{2}{*}{$\begin{array}{c}\text { Categories } \\
(O E W, F E W, \\
N E W)\end{array}$} & \multicolumn{2}{|c|}{$\frac{\partial u}{\partial O E W}$} & \multicolumn{2}{|c|}{$\frac{\partial u}{\partial F E W}$} & \multicolumn{2}{|c|}{$\frac{\partial u}{\partial N E W}$} \\
\hline & Value & Std. error & Value & Std. error & Value & Std. error \\
\hline & \multicolumn{6}{|c|}{ (1) Model without TA dummies } \\
\hline 1 & $0.369 * * *$ & 0.024 & $0.044^{* *}$ & 0.016 & $0.087 * * *$ & 0.019 \\
\hline 2 & $0.313^{* * *}$ & 0.017 & 0.011 & 0.012 & $0.064 * * *$ & 0.013 \\
\hline 3 & $0.258 * * *$ & 0.018 & -0.021 & 0.018 & $0.041 * *$ & 0.019 \\
\hline 4 & $0.203 * * *$ & 0.028 & $-0.054^{*}$ & 0.028 & 0.018 & 0.031 \\
\hline \multirow[t]{2}{*}{5} & $0.147 * * *$ & 0.039 & $-0.086^{*}$ & 0.039 & -0.005 & 0.044 \\
\hline & \multicolumn{6}{|c|}{ (2) Model with TA dummies } \\
\hline 1 & $0.511 * * *$ & 0.026 & $0.047 * *$ & 0.017 & 0.026 & 0.020 \\
\hline 2 & $0.441 * * *$ & 0.018 & -0.007 & 0.013 & 0.010 & 0.014 \\
\hline 3 & $0.370 * * *$ & 0.020 & $-0.062 * * *$ & 0.019 & -0.006 & 0.021 \\
\hline 4 & $0.300 * * *$ & 0.030 & $-0.117 * * *$ & 0.029 & -0.022 & 0.033 \\
\hline 5 & $0.229 * * *$ & 0.042 & $-0.172 * * *$ & 0.041 & -0.037 & 0.047 \\
\hline
\end{tabular}

Note: ${ }^{*}$ is significant at $10 \%$ level; ${ }^{* *}$ at $5 \%$ level; ${ }^{* * *}$ at $1 \%$ level.

Table 7: Rural-urban split for Test 2

\begin{tabular}{lcccccccc}
\hline & \multicolumn{4}{c}{$\mathbf{c}$ Rural } & \multicolumn{2}{c}{ Urban } \\
& Coeff. & $\begin{array}{c}\text { Std. } \\
\text { error }\end{array}$ & Coeff. & $\begin{array}{c}\text { Std. } \\
\text { error }\end{array}$ & Coeff. & $\begin{array}{c}\text { Std. } \\
\text { error }\end{array}$ & Coeff. & $\begin{array}{c}\text { Std. } \\
\text { error }\end{array}$ \\
\hline OEW & $0.491^{* * *}$ & 0.042 & $0.575^{* * *}$ & 0.045 & $0.423^{* * *}$ & 0.079 & $0.458^{* * *}$ & 0.087 \\
FEW & $0.137^{* * *}$ & 0.036 & 0.023 & 0.039 & 0.108 & 0.066 & -0.000 & 0.071 \\
NEW & $0.117^{* * *}$ & 0.028 & $0.112^{* * *}$ & 0.030 & -0.013 & 0.061 & 0.036 & 0.065 \\
OEW.FEW & $-0.046^{* *}$ & 0.014 & $-0.053^{* * *}$ & 0.015 & -0.026 & 0.025 & -0.038 & 0.026 \\
OEW.NEW & $-0.038^{*}$ & 0.017 & -0.005 & 0.018 & -0.019 & 0.027 & -0.007 & 0.029 \\
\hline N & 9,071 & & 9,071 & & 2,148 & & 2,148 & \\
Pseudo-R2 & 0.028 & & 0.137 & & 0.069 & & 0.191 & \\
\hline
\end{tabular}

Note: Controls included, as in Table 5. 


\section{Table 8: Poverty lines for own-economic welfare holding utility constant}

(a) At the boundary between "unsatisfied" and "neither unsatisfied nor satisfied"

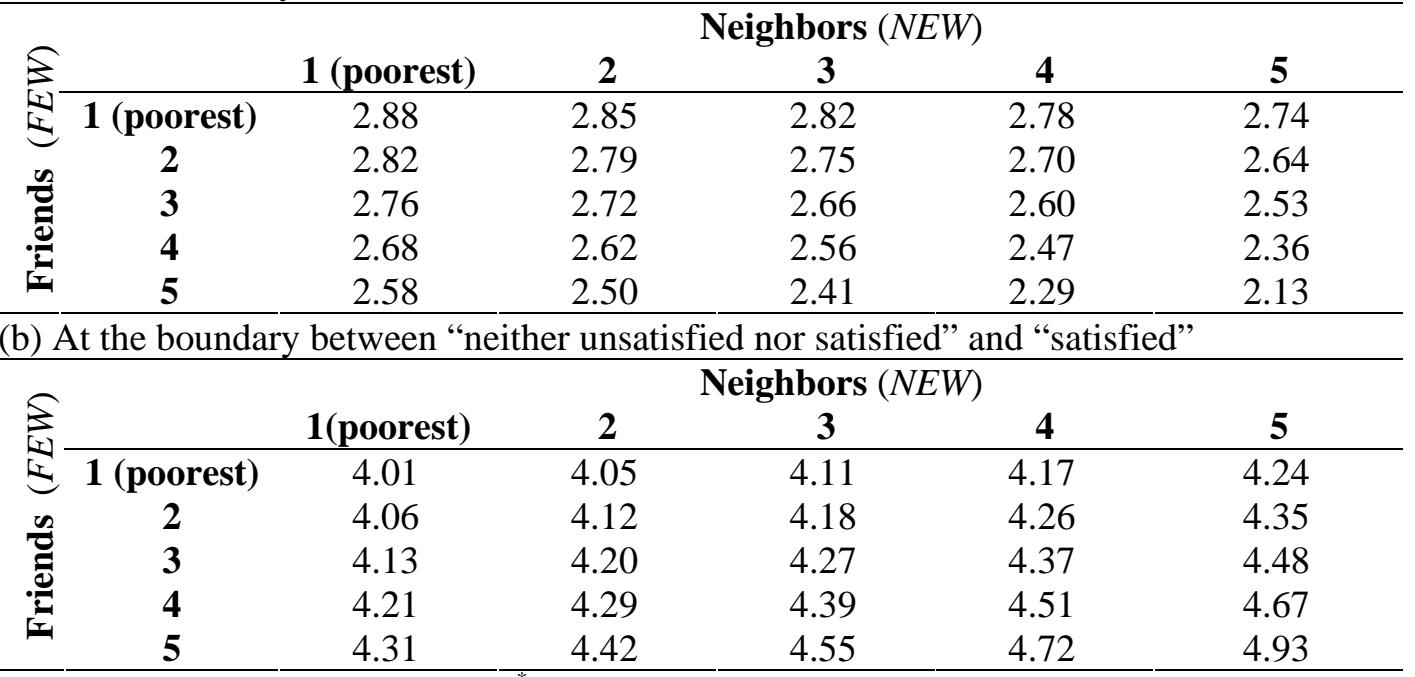

Note: The table gives the value $O E W^{*}$ needed to compensate for each (NEW, FEW) combination holding the expected value of utility constant. Controls set to mean points. 
Figure 1: Value of gifts received as a proportion of total consumption
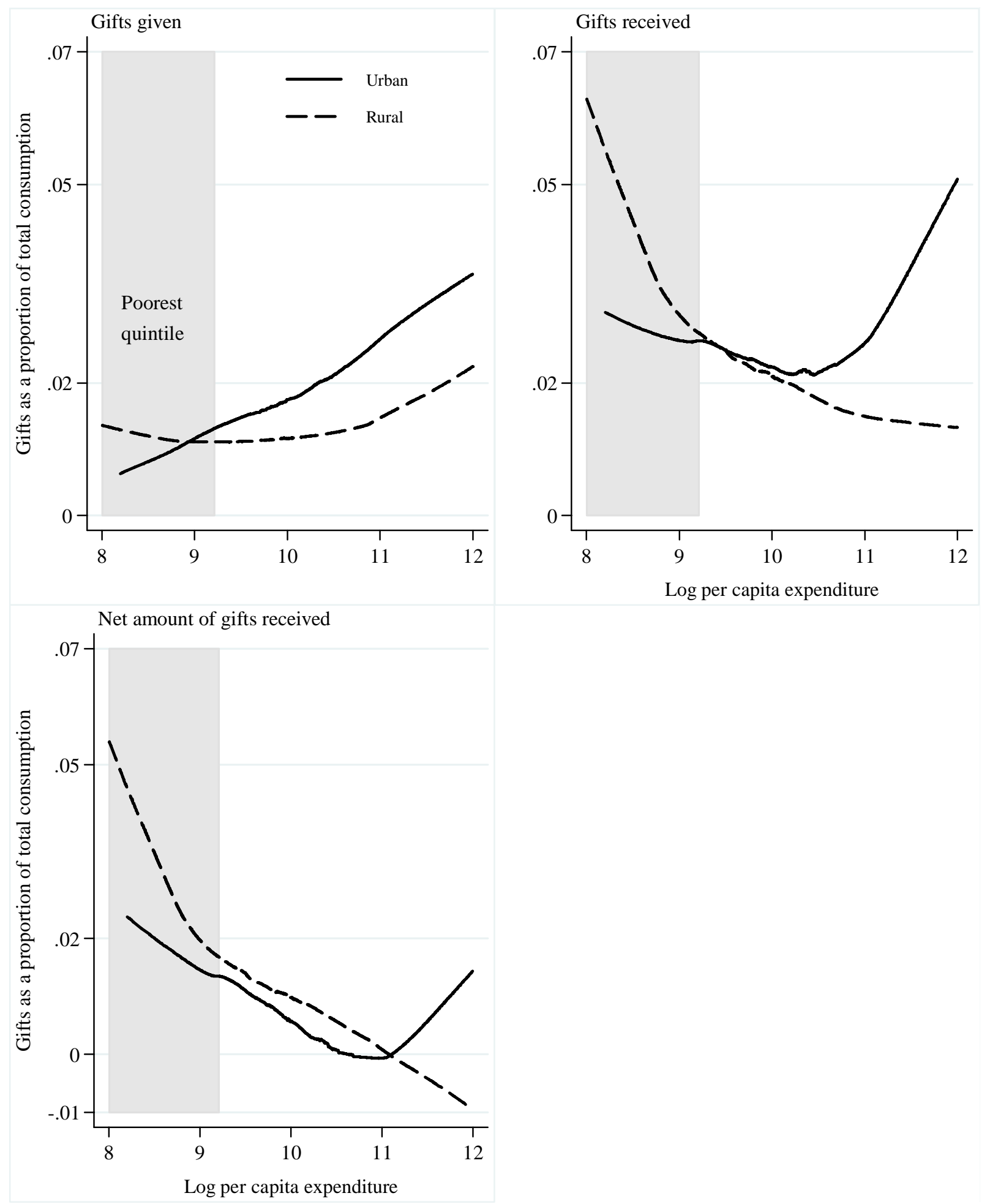
Figure 2: Days of ganyu labor and proportion of consumption accounted for by income from ganyu
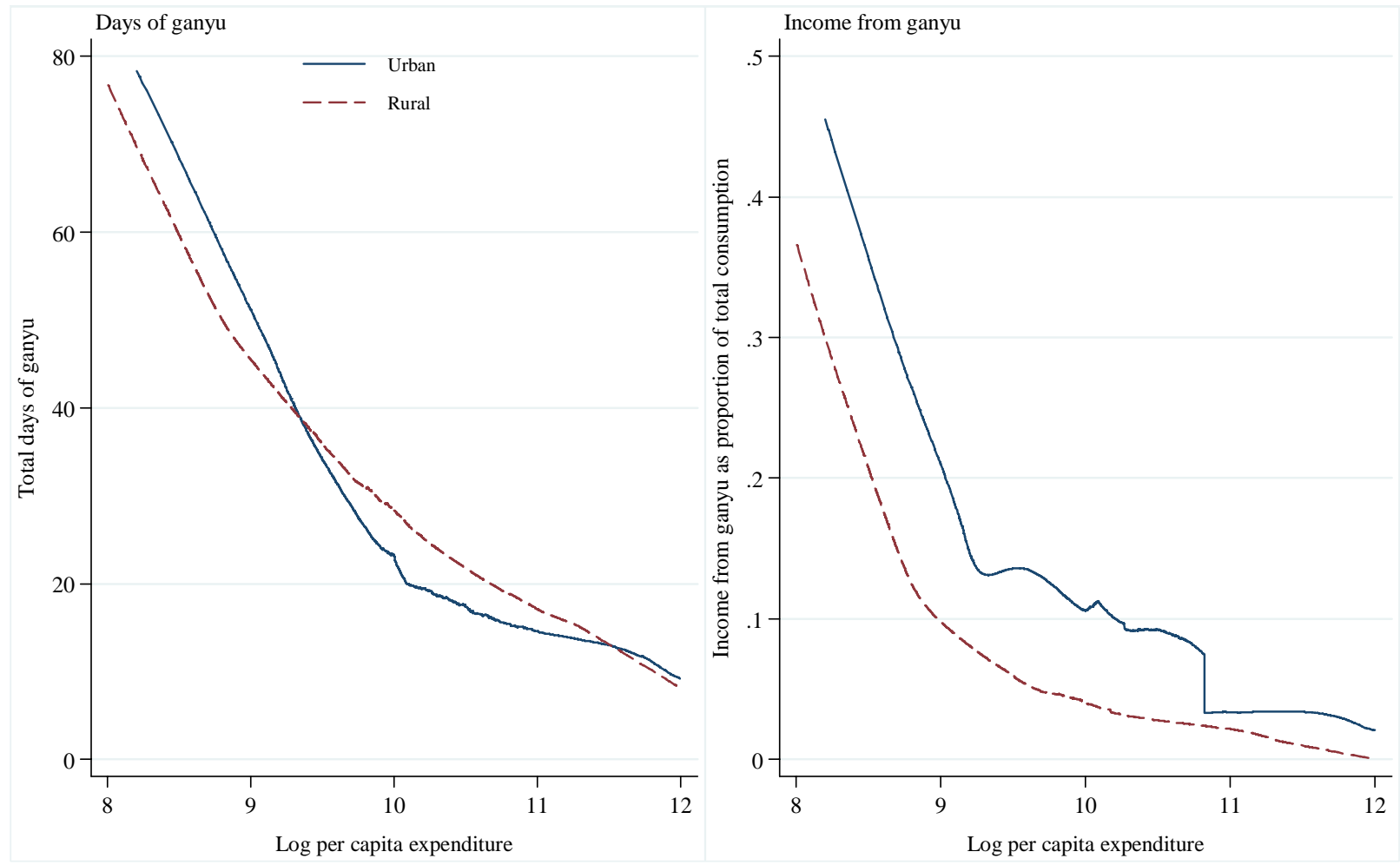
Figure 3: Length of residence and log consumption per person

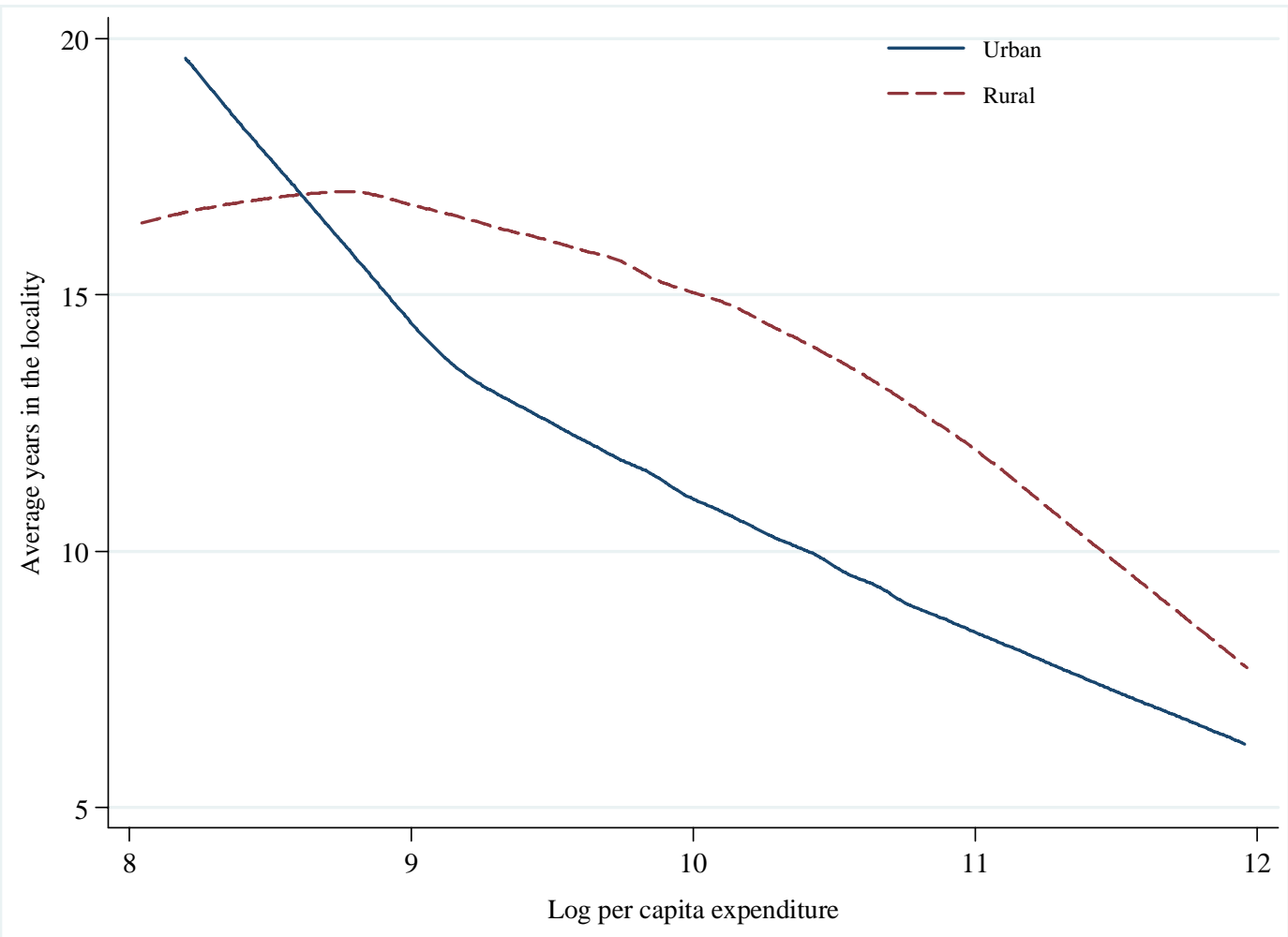


Figure 4: Nonparametric regressions of satisfaction with life against log consumption per person
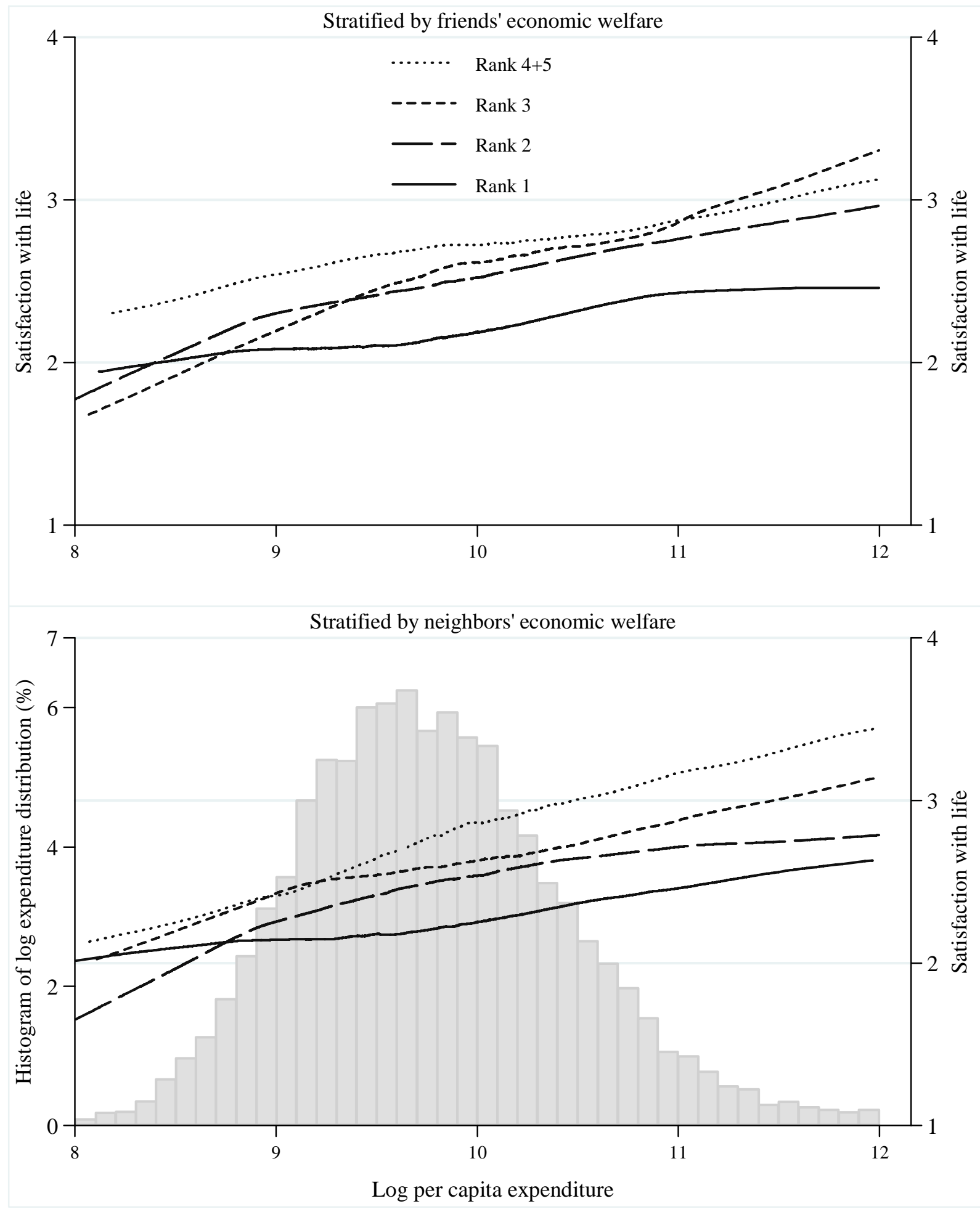